\title{
Alterações na proteostase de células endoteliais pulmonares em pacientes com hipertensão pulmonar tromboembólica crônica
}

Tese apresentada à Faculdade de Medicina da Universidade de São Paulo para obtenção do título de Doutor em Ciências

Programa de Pneumologia

Orientador: Prof. Dr. Mário Terra Filho

\section{São Paulo}


Dados Internacionais de Catalogação na Publicação (CIP)

Preparada pela Biblioteca da

Faculdade de Medicina da Universidade de São Paulo

Creprodução autorizada pelo autor

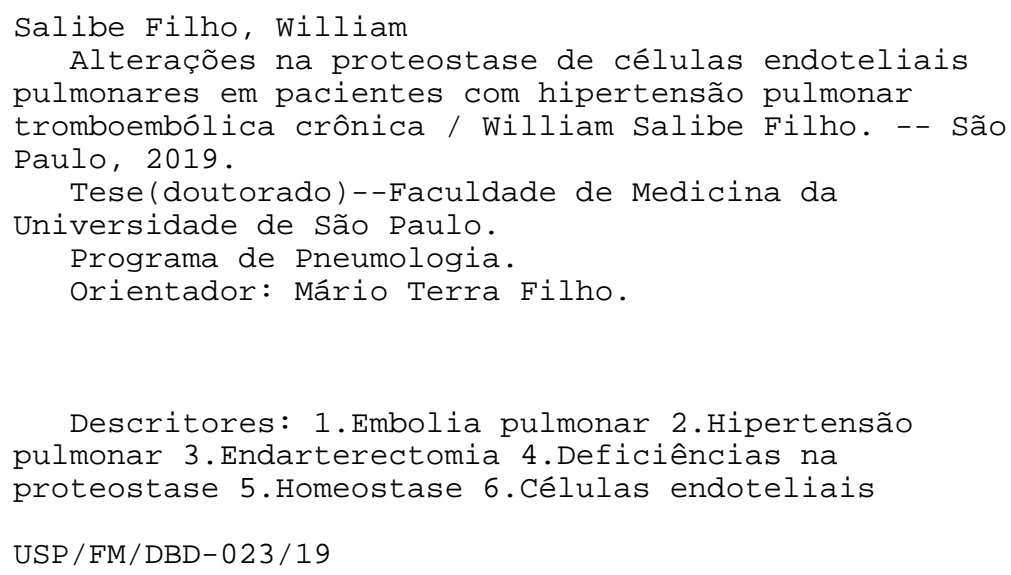


Dedicatória 
Dedico este trabalho, primeiramente, a meus pais William e Maria Helena, que me ensinaram o valor do aprendizado e do conhecimento para o crescimento pessoal e profissional.

A minha querida Maria Carolina, pelo apoio incondicional em todos os momentos, difíceis ou fáceis.

A Isabella, Marcella e Fabiana que estiveram a meu lado, desde sempre.

A meus professores e amigos que estiveram presentes em toda a minha formação. 
Agradecimentos 
Inicialmente tenho que agradecer a Deus por me iluminar e proteger dos desafios diários e pela oportunidade de realizar este sonho.

A meus pais, William Salibe e Maria Helena Cavinatto Salibe, pois sem seus esforços e ajuda nada disto teria acontecido. Deram-me todo o suporte, orientando-me de uma forma a me fazer sempre refletir, aprender e a enfrentar desafios. Meu pai mostrou-me o que era a Medicina desde que eu era pequeno, ensinando-me o caminho da ética e da competência, é meu exemplo de médico. Minha mãe, com seu jeito otimista, fez-me acreditar que, para quase tudo na vida, temos um jeito de resolver, sempre de maneira correta, e, como ela diz: "calma, meu filho, as coisas vão dar certo". E, no final, deram, mãe. Muito obrigado a vocês.

A minhas irmãs, Isabella, Marcella e Fabiana, que me auxiliaram e apoiaram nesta caminhada.

A Maria Carolina (Carol), a meu lado nos momentos difíceis, com quem compartilhava minhas angústias, sempre me incentivando a continuar, muito obrigado pelo apoio e ajuda, você foi fundamental.

À Dra. Mônica S. Lapa, por meio de quem conheci o "mundo das células"; com certeza me ajudou a realizar este sonho.

Ao Grupo de Circulação Pulmonar, por me aceitar e auxiliar, especialmente ao Prof. Dr. Rogério de Souza, pelas excelentes discussões acadêmicas e, principalmente, pelos ensinamentos compartilhados. Ao Dr. Caio Júlio Cesar Fernandes que ajudou em minha qualificação e elevou o nível desta pesquisa e a todos os que participaram das reuniões de segunda, pois aumentaram meu conhecimento sobre hipertensão pulmonar. 
Ao Programa de Pneumologia da FMUSP, que me acolheu com todo o apoio possível para esta pesquisa, e ao Prof. Dr. Carlos Carvalho, sempre presente, quando precisei.

À Equipe Cirúrgica, que me auxiliou no fornecimento do material, ao Prof. Dr. Fábio B. Jatene, pelas discussões cirúrgicas, e ao Dr. Orival Freitas Filho que, de forma muito prestativa, sempre me ajudou.

Ao laboratório do $10^{\circ}$ andar, local onde realizei as pesquisas e tive 0 suporte de todos, fornecendo-me experiência e aprendizado. Ao Laboratório de Pleura que, com certeza, fez parte constante de minha vida nos últimos cinco anos e, claro, à Dra. Lisete Teixeira e à Dra. Milena Acencio que me aceitaram e ajudaram, sempre de forma muito carinhosa. Não poderia esquecer de Vanessa Alvarenga e de Carlos Sérgio Silva que me apoiaram nos experimentos, mas também no incentivo moral em horas difíceis.

Ao laboratório do $9^{\circ}$ andar, que também me acolheu e auxiliou em vários dos experimentos realizados, ao Dr. Victor Debbas, pela ajuda, ao Prof. Dr. Francisco Laurindo, por todo o auxílio nesta pesquisa. Meu especial agradecimento à Dra. Thaís Araújo que, num encontro casual, no laboratório, perguntou-me o que eu fazia e, a partir desse momento trabalhamos juntos, isto fez com que a qualidade deste estudo elevasse seu patamar, muito obrigado por toda a ajuda.

Por fim, meu agradecimento mais que especial ao Prof. Dr. Mário Terra Filho que, durante os anos em que estive no doutorado, sempre esteve a meu lado, ajudando de forma intelectual, mas também ensinando Medicina, tanto a conduzir um paciente de forma científica, quanto mostrando que muitas vezes a empatia é fundamental, não tenho dúvidas de que sou outro médico após esses anos no ambulatório. Também sentirei saudades de nossas segundas, quando discutíamos sobre tantos assuntos. Com certeza o senhor não me ensinou só Medicina, mostrou-me o que é a vida acadêmica, quais cuidados devemos ter e a entender como funciona uma universidade. Querido Professor Mário, também 
tenho que lhe agradecer pelos ensinamentos além dos acadêmicos, com certeza fizeram parte de minha formação, com nossas discussões nas reuniões 'extrahospitalares', durante as quais conversávamos sobre tudo e, claro, apreciando um bom cafezinho... Muito obrigado por toda a ajuda.

Finalmente agradeço a todos que, de alguma forma, ajudaram e torceram por mim, com certeza citar todos os nomes aqui seria algo impossível. 
Epígrafe 
"A mente que se abre a uma nova ideia jamais voltará ao seu tamanho original" 
Normatização adotada 
Esta tese está de acordo com as seguintes normas, em vigor no momento de sua publicação:

Referências: adaptado de International Committee of Medical Journals Editors (Vancouver).

Universidade de São Paulo. Faculdade de Medicina. Divisão de Biblioteca e Documentação. Guia de apresentação de dissertações, teses e monografias. Elaborado por Anneliese Carneiro da Cunha, Maria Julia de A.L.Freddi, Maria F.Crestana, Marinalva de Souza Aragão, Suely Campos Cardoso, Valéria Vilhena. $3^{a}$ ed. São Paulo: Divisão de Biblioteca e Documentação; 2011. Abreviatura dos títulos e periódicos de acordo com List of Journals Indexed in Index Medicus. 
Sumário 
Lista de abreviaturas e siglas

Lista de figuras

Lista de tabelas

Resumo

Abstract

1

INTRODUÇÃO.

01

1.1 Hipertensão pulmonar tromboembólica crônica (HPTEC)............... 02

1.2 Mecanismos fisiopatológicos da HPTEC.................................... 02

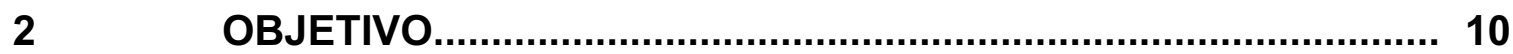

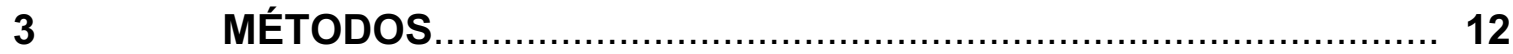

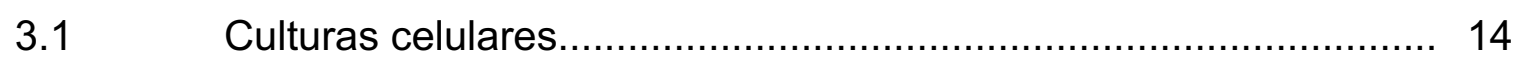

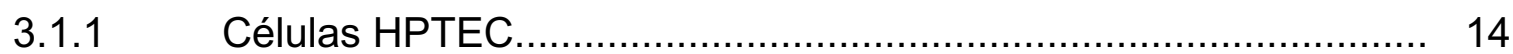

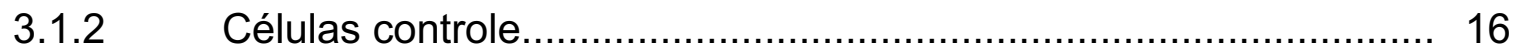

3.2 Marcações com anticorpos...................................................... 17

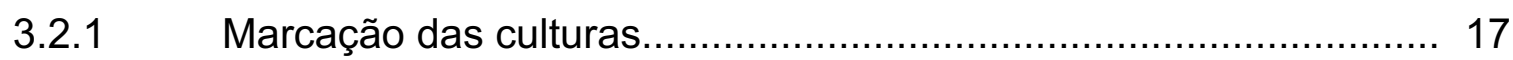

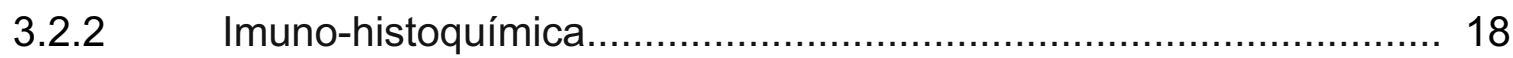

3.3 Método de stress celular ............................................................ 18

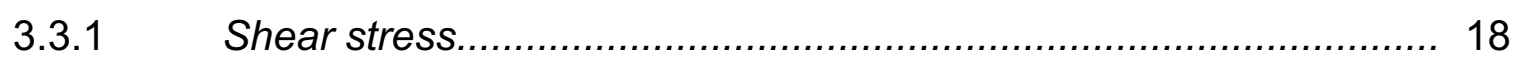

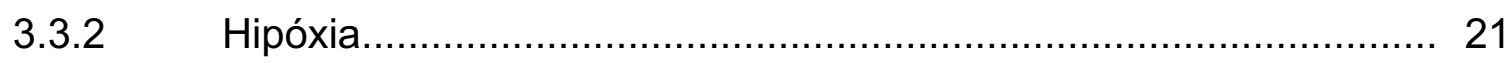

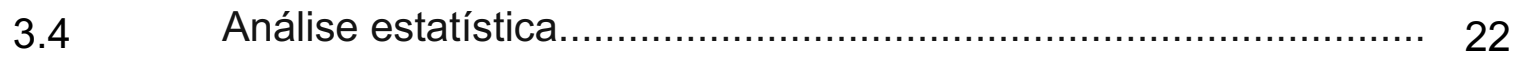

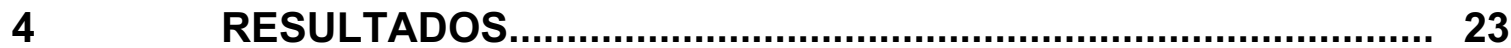

4.1 Culturas extraídas dos trombos................................................. 24

4.2 Marcação das culturas........................................................... 25

4.3 Experimentos com shear stress............................................ 25

$4.4 \quad$ Experimentos submetidos à hipóxia............................................ 34

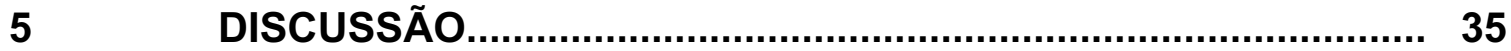

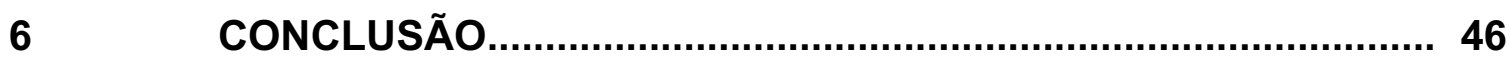

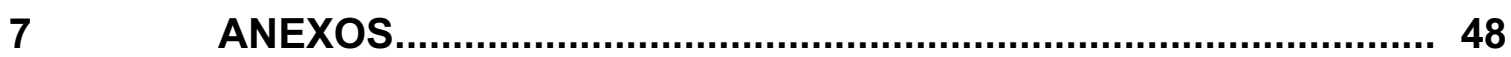

$8 \quad$ REFERÊNCIAS ............................................................... 51 


\section{Listas}


A2

BD

BIP

CE

CD

EGM

GMP

GRP

HAP

HP

HPTEC

HSP

NOS

eNOS

NO

$\mathrm{NO}_{2}$

$\mathrm{NO}_{3}$

PBS

PDI

PECAM-1

PN

RPM

RE

SAAF

TEAP

SFB
Anexina A2

Becton Dickinson

Binding immunoglobulin protein

Células endoteliais

Cluster de diferenciação

Endothelial cell growth medium

Monofosfato cíclico de guanosina

Glucose-regulated protein

Hipertensão arterial pulmonar

Hipertensão pulmonar

Hipertensão pulmonar tromboembólica crônica

Heat Shock Protein

Óxido nítrico sintase

Óxido nítrico sintase endotelial

Óxido nítrico

Nitrito

Nitrato

Phosphate buffered saline

Dissulfeto isomerase proteica

Molécula de adesão de células endoteliais de plaquetas

1

Plasmina

Rotações por minuto

Retículo endoplasmático

Síndrome do anticorpo antifosfolípide

Tromboendarterectomia pulmonar

Soro fetal bovino 
Figura 1 Avaliação do shear stress na circulação pulmonar, adaptado de Happé et al ${ }^{19}$

Figura 2 Esquema de produção de NO, adaptado Vanhoutte et $a^{\beta 5}$ 06

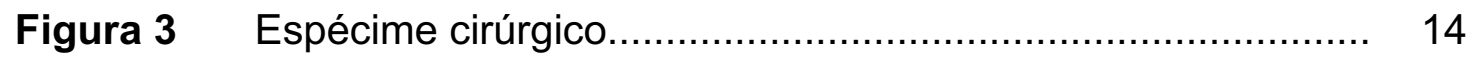

Figura 4 Método de extração por colagenase................................ 15

Figura 5 Placa de seis poços com esquematização da colocação dos fragmentos do trombo.................................................. 16

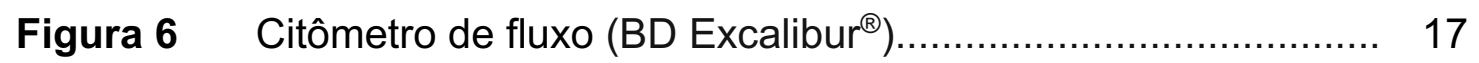

Figura 7 Aparelho de shear stress modelo cone-placa...................... 19

Figura $8 \quad$ Protocolo de shear stress...................................... 19

Figura 9 Protocolo de hipóxia................................................ 22

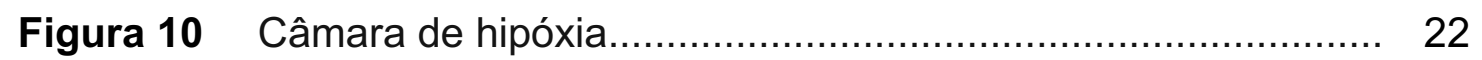

Figura 11 Controladores de $\mathrm{CO}_{2}$ e $\mathrm{O}_{2}$, respectivamente $5 \%$ e 1\%........ 22

Figura 12 Fotos das culturas das células extraídas dos trombos........... 24

Figura 13 Fotos das culturas de dois pacientes com HPTEC e CE........ 24

Figura 14 Marcação de CD31e CD90, analisadas em citometria de fluxo................................................................... 25

Figura 15 Foto com morfologia dos grupos CE e HPTEC................... 26

Figura 16 Efeito do shear stress na expressão proteica de eNOS, produção de NO e na morte celular.................................. 27

Figura 17 Expressão de caveolina 1, Alpha 5 integrina e HSP 90 na condição estática....................................................... 28

Figura 18 Efeito do shear stress na expressão proteica de GRP94....... 29

Figura 19 Efeito do shear stress na expressão proteica de GRP78(BIP) e PDI .................................................................. 30

Figura 20 Efeito do shear stress na expressão proteica de HSP70....... 31

Figura 21 Efeito do shear stress na expressão proteica da anexina A2 32 
Figura 22 Marcação por imuno-histoquímica com HSP70 e anexina A2 na parte interna da artéria pulmonar dos portadores de HPTEC e artéria pulmonar de doadores de transplante pulmonar.

Figura 23 Quantificação da produção de NO do meio condicionado pré e pós vinte e quatro horas de hipóxia. 
Tabela 1 Proteínas estudadas que participam da proteostase celular.... 8

Tabela 2 Dados clínicos e hemodinâmicos dos pacientes de quem os trombos foram extraídos 
Resumo 
Salibe Filho W. Alterações na proteostase de células endoteliais pulmonares em pacientes com hipertensão pulmonar tromboembólica crônica [tese]. São Paulo: Faculdade de Medicina, Universidade de São Paulo; 2019.

Introdução: A hipertensão pulmonar tromboembólica crônica (HPTEC) está incluída no grupo 4 da Classificação Internacional de Hipertensão Pulmonar (HP). É caracterizada pela persistência de obstrução por trombos sanguíneos na circulação pulmonar, associada à presença de HP, após três meses de anticoagulação efetiva. $O$ tratamento de escolha é a cirurgia de tromboendarterectomia pulmonar (TEAP), mas alguns dos mecanismos fisiopatológicos envolvidos nesta forma de hipertensão ainda permanecem incertos. O redirecionamento dos fluxos sanguíneos pulmonares e a hipóxia exercem papel importante na HPTEC, como também em casos de hipertensão pulmonar residual, após a cirurgia de TEAP. Entretanto, existem poucos dados sobre as respostas das células endoteliais pulmonares a essas mudanças de fluxo e de oxigenação, surgindo a necessidade do estudo da proteostase celular nesta doença. Objetivo: (A) Caracterização morfológica das células em culturas provenientes de artéria pulmonar de pacientes com HPTEC submetidos à TEAP. (B) Avaliação da resposta das células endoteliais, a partir da análise de proteínas envolvidas na proteostase celular, quando submetidas a diferentes níveis de stress mecânico e à hipóxia. Método: Trombos extraídos por TEAP foram processados, as células retiradas foram cultivadas, marcadas com CD31 e submetidas a stress mecânico por vinte e quatro horas, constituindo o grupo HPTEC. A proteostase celular foi avaliada pela medida de proteínas expressas por essas células, tanto em culturas quanto pela análise imuno-histoquímica do tecido vascular pulmonar. Como grupo controle foram utilizadas células endoteliais pulmonares humanas de linhagem (CE) e tecido de artérias pulmonares de doadores de transplante de pulmão. As culturas de ambos os grupos também foram colocadas em hipóxia e analisada a expressão indireta de óxido nítrico (NO) por meio da medida de nitrato. Resultado: as células do grupo HPTEC com morfologia endotelial foram marcadas positivamente com CD31 e apresentaram características semelhantes às do 
grupo CE. Em relação ao stress mecânico, na condição estática as células HPTEC expressaram menor quantidade de óxido nítrico sintase endotelial (eNOS). Quando submetidas a stress de alta intensidade (shear stress $\geq 15$ dynes $/ \mathrm{cm}^{2}$ ), as reduções ficaram ainda mais evidentes, sinalizando uma disfunção endotelial. Na análise de outras proteínas, como GRP94, GRP78, HSP70, as respostas também foram menores no alto fluxo. Na avaliação imunohistoquímica da camada íntima do vaso pulmonar, a HSP70 apresentava-se diminuída, corroborando os achados das culturas. Os valores de NO foram inferiores no grupo HPTEC quando se comparam hipóxia e normóxia. Conclusão: (A) A avaliação morfológica mostrou que as culturas de células HPTEC eram endoteliais. (B) A análise funcional revelou que estas células apresentaram redução de resposta, o que caracteriza alteração da proteostase, que se tornou mais evidente quando foram submetidas a shear stress de alta magnitude. A hipóxia reduziu a produção de NO, entretanto sem diferenciar os grupos celulares estudados.

Descritores: embolia pulmonar; hipertensão pulmonar; endarterectomia, deficiências na proteostase; homeostase; células endoteliais. 
Abstract 
Salibe Filho W. Alterations in proteostasis of endothelial cells in patients with chronic thromboembolic pulmonary hypertension [thesis]. São Paulo: "Faculdade de Medicina, Universidade de São Paulo"; 2019.

Introduction: Chronic Thromboembolic Pulmonary Hypertension (CTEPH) is included in group 4 of the International Classification of Pulmonary Hypertension $(\mathrm{PH})$. It is characterized by persistent obstruction by blood clots in the pulmonary circulation, associated with the presence of $\mathrm{PH}$, after 3 months of effective anticoagulation. The treatment of choice is pulmonary endarterectomy (PEA). However, some of the pathophysiological mechanisms involved in this form of hypertension still remain uncertain. The redirection of pulmonary blood flow and hypoxia play an important role in CTEPH, and also, in cases of residual pulmonary hypertension after PEA surgery. Nevertheless, there is insufficient data from the pulmonary endothelial cell responses to this flow and oxygenation changes, reflecting the need to further study of cellular proteostasis in this disease. Objective: (A) Morphological characterization of cells in cultures from the pulmonary artery of CTEPH patients submitted to PEA. (B) Evaluation of the response of endothelial cells, through the analysis of proteins involved in cellular proteostasis, when submitted to different levels of mechanical stress and hypoxia. Method: Thrombus extracted by PEA were processed and the cells removed were cultured, marked with CD31 and submitted to mechanical stress for 24 hours and constituted the group CTEPH. Cellular proteostasis was measured by the quantification of the proteins expressed in cultures and in pulmonary vascular tissue by immunohistochemistry analysis. As a control group, the human pulmonary endothelial cells (EC) and pulmonary artery tissue from lung transplant donors were used. Cultures of both groups were also placed in hypoxia and the indirect expression of nitric oxide (NO) was analyzed by nitrate measurement. Results: The cells with endothelial morphology from the CTEPH group were positively marked with CD31 and presented similar characteristics as the EC group. Regarding mechanical stress, in the static condition, the CTEPH cells expressed a lesser amount of endothelial nitric oxide synthase (eNOS). When submitted to high flow (shear stress $>15$ dynes $/ \mathrm{cm}^{2}$ ) the reductions became even more evident, signaling an endothelial dysfunction. In the analysis 
of other proteins, such as GRP94, GRP78, HSP70, responses were also lower in high shear stress. In the immunohistochemistry analysis of the intimal layer of the pulmonary vessel HSP70 was diminished, corroborating with the findings of the cultures. The NO values were lower in the CTEPH group when compared hypoxia and normoxia. Conclusion: (A) Morphological evaluation showed that cultures of CTEPH cells were endothelial. (B) Functional analysis revealed that these cells had reduced response, which characterizes proteostasis alterations, which became more evident when they underwent shear stress of high magnitude. Hypoxia reduced NO production, however without differentiating the cell groups studied.

Descriptors: pulmonary embolism; hypertension, pulmonary; endarterectomy; proteostasis deficiencies; homeostasis; endothelial cells 
1. Introdução 


\subsection{Hipertensão pulmonar tromboembólica crônica (HPTEC)}

A HPTEC faz parte do Grupo 4 da Classificação Internacional de Hipertensão Pulmonar ${ }^{(1)}$, é caracterizada por uma obliteração parcial ou total dos vasos pulmonares, por trombos ${ }^{(2)}$. Para seu diagnóstico é preciso a presença de HP, associada a, pelo menos, um defeito segmentar de perfusão, após três meses de anticoagulação, no mínimo(3). Depois de um evento agudo de embolia pulmonar, a maior parte dos casos evolui para resolução espontânea; entretanto, a HPTEC aparece como complicação tardia entre $0,1 \%$ a $9,1 \%$ dos $\operatorname{casos}^{(4)}$. Numa estimativa para a população norte-americana, a incidência seria de 1/200.000 habitantes, com 1.600 novos casos por ano ${ }^{(3)}$. Os mecanismos responsáveis pela não resolução de êmbolos agudos não foram completamente identificados $^{(3,5)}$; portanto, a obtenção de mais informações sobre sua fisiopatologia pode ajudar na compreensão da doença.

O tratamento de escolha para a HPTEC é o cirúrgico, por meio da $\operatorname{TEAP}^{(6,7)}$, procedimento com grande potencial curativo. Entretanto, mais de $30 \%$ dos pacientes operados podem persistir com HP residual e os mecanismos envolvidos na manutenção do quadro hipertensivo ainda permanecem incertos ${ }^{(6,}$ 8). Por este motivo, é importante a realização de estudos fisiopatológicos mais detalhados sobre esta disfunção vascular pulmonar.

\subsection{Mecanismos fisiopatológicos da HPTEC}

Diversas teorias foram descritas com o propósito de explicar a não resolução dos trombos: anticoagulação inadequada, alterações na fibrinólise, infecção por Staphylococcus aureus, alterações na molécula de adesão de células endoteliais de plaquetas 1(PECAM-1) e o redirecionamento de fluxos sanguíneos na circulação pulmonar ${ }^{(9-12)}$. Dorfmüller et al(13) descreveram alteração das veias pulmonares, pelo remodelamento fibrótico reativo da parede 
do vaso, relacionando a pressão sistêmica com o sistema venoso de baixa pressão do pulmão, demonstrando que as alterações vão além do leito arterial pulmonar. Numa revisão recente sobre a fisiopatologia da HPTEC, também foi descrito um acometimento das arteríolas pulmonares semelhante aos observados na hipertensão arterial pulmonar $(\mathrm{HAP})^{(14)}$. Este processo é caracterizado por uma multiplicação de capilares alveolares, identificando o acometimento da microvasculatura pulmonar, porém sem esclarecer totalmente qual é o real envolvimento da camada íntima do vaso, especialmente das células endoteliais.

Em 1993, Moser et al(15) descreveram a teoria dos dois compartimentos no leito vascular pulmonar de pacientes com HPTEC, um comprometido por obstrução e submetido a uma isquemia crônica, e outro decorrente da redistribuição de fluxo sanguíneo para um território desobstruído, induzindo um aumento da tensão nestes vasos. Este redirecionamento dos fluxos vasculares acarreta o remodelamento das paredes das artérias pulmonares; e, associado à vasoconstricção local secundária à hipóxia, promove alterações que reduzem o leito vascular. Esta ação provoca uma das mais graves consequências da doença, a sobrecarga do ventrículo direito( ${ }^{(16)}$.

O endotélio vascular que reveste a superfície luminal de todo os vasos sanguíneos é constantemente exposto a uma força de cisalhamento (shear stress) exercida pelo sangue que flui ${ }^{(17)}$. Quando se analisa a circulação sistêmica, o fluxo elevado ( $\geq 15$ dynes $/ \mathrm{cm}^{2}$ ), chamado de cisalhamento laminar, confere proteção, e o oscilatório, que é o baixo $\left(<5 d y n e s / \mathrm{cm}^{2}\right)$, pode promover disfunção endotelial, contribuindo para a doença cardiovascular $\left.{ }^{17}{ }^{17}{ }^{18}\right)$. Esta tensão de cisalhamento também é identificada na artéria pulmonar, como demonstrado na Figura $1^{(19)}$; entretanto, o alto fluxo acarreta um efeito oposto ao sistêmico, induzindo agravamento da doença, remodelamento vascular com disfunção endotelial( ${ }^{(9)}$. 


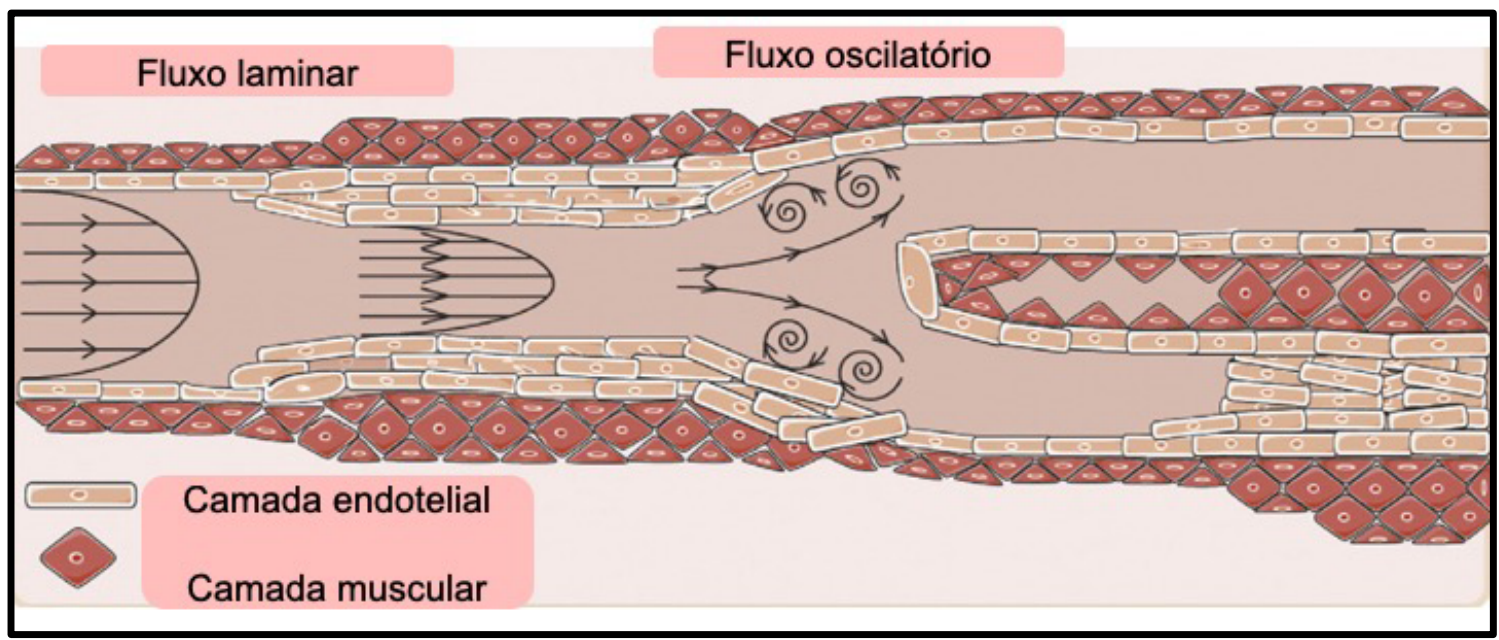

Figura 1- Avaliação do shear stress na circulação pulmonar (adaptado de Happé CM. et al Vascul Pharmacol. 2016) (19)

Foi demonstrado previamente na HPTEC que o trombo retirado por TEAP é composto por células endoteliais, musculares e miofibroblastos ${ }^{(2)}$, e acredita-se que essas células teriam características diferentes de células de artérias pulmonares sem doença. Seriam mais resistentes à apoptose por perda da sinalização de sua sobrevivência ${ }^{(20)}$; consequentemente, teriam um estímulo à proliferação desordenada(21), semelhante ao que ocorre em pacientes com HAP idiopática ${ }^{(22)}$.

A homeostase proteica, ou proteostase, é a maneira pela qual as células respondem rapidamente ao ambiente em que estão inseridas, mantendo as funções que permitem uma atividade biológica adequada(23, 24). Embora as propriedades químicas, bioquímicas e biofísicas de uma proteína regulem sua função, os mecanismos envolvidos não são estáticos e variam de acordo com o enovelamento proteico, essencial para ativação e funcionamento celular. As expressões proteicas são dinâmicas, podendo se modificar pelo ambiente local ao qual as células são expostas. Essas mudanças alteram a função das proteínas e ajudam a mediar algumas das respostas de curto e longo prazo que garantem a sobrevivência celular ${ }^{(25,26)}$. Portanto, o estudo da proteostase é importante para o entendimento da fisiopatologia de uma série de doenças.

As células endoteliais são organizadas como uma monocamada margeando o lúmen interno do vaso, em contato direto com o fluxo sanguíneo, 
apresentando diversas propriedades, grande capacidade regenerativa, controle do transporte celular, permeabilidade e reparação pós-lesão(27, 28), todos dependentes diretamente da proteostase. Em cultura, as células endoteliais são arredondadas, ovaladas, mas in vivo sua morfologia é alongada, por alinharemse ao fluxo de sangue. Em resumo, esta camada celular pode ser descrita como a interface sensora e transdutora de forças biomecânicas intravasculares ${ }^{(27)}$. Após a descoberta das funções do endotélio, principalmente o entendimento da liberação do óxido nítrico (NO), na década de $1980^{(29)}$, houve grande mudança na compreensão da fisiologia da circulação sanguínea ${ }^{(30)}$. Naquela época, em estudos com ratos e humanos, percebeu-se que havia muito mais nitrito $\left(\mathrm{NO}_{2}{ }^{-}\right)$ e nitrato $\left(\mathrm{NO}_{3}{ }^{-}\right)$circulante do que a ingesta, deixando claro que essas substâncias eram produzidas em algum local do corpo ${ }^{(31,32)}$. Alguns anos depois foi descrito que a degradação do NO resultava na liberação de nitrito e nitrato ${ }^{(33)}$, portanto a dosagem destes marcadores poderia, de forma indireta, avaliar sua produção(34). O NO é um potente vasodilatador pulmonar, que age a partir da estimulação da guanilato ciclase solúvel, aumentando monofosfato cíclico de guanosina (GMP cíclico). Promove o relaxamento da musculatura e consequente dilatação dos vasos ${ }^{(33,34)}$, produzindo efeito oposto à vasoconstrição exercida pelo sistema nervoso simpático e renina-angiotensina ${ }^{(33)}$.

De todas as células encontradas na artéria pulmonar, as endoteliais são as únicas que produzem óxido nítrico ${ }^{(34)}$. Sua geração depende da proteína óxido nítrico sintase (NOS), que tem três isoenzimas, NOS I ou nNOS, NOS II ou iNOS e NOS III ou eNOS; a primeira expressa por células neuronais centrais e periféricas; a segunda, por macrófagos e a terceira, por células endoteliais, conhecida como NOS endotelial. Todas são ativadas pelo cálcio $\left(\mathrm{Ca}^{2+}\right)$, exceto eNOS que, além do $\mathrm{Ca}^{2+}$, pode ser ativada pelo shear stress, considerado o principal estímulo fisiológico para produção de $\mathrm{NO}$ in vivo(27). Na forma inativa a eNOS fica ligada à caveolina-1, ambas localizadas na membrana celular (Figura $2)^{(35)}$. A situação de alto fluxo promove a estimulação da proteína de choque térmico 90 (Heat Shock Protein - HSP) que, localizada no citoplasma, tem função de separar a caveolina-1 da eNOS, ativando-a(36). Entretanto, para seu bom funcionamento, é necessário um enovelamento proteico adequado, que 
consiste na propriedade de a proteína adquirir sua configuração funcional. No processo de produção de NO, a proteína regulada pela glicose (GRP) 94, localizada no retículo endoplasmático (RE), participa do enovelamento da HSP90 para liberação da eNOS ${ }^{(37)}$.

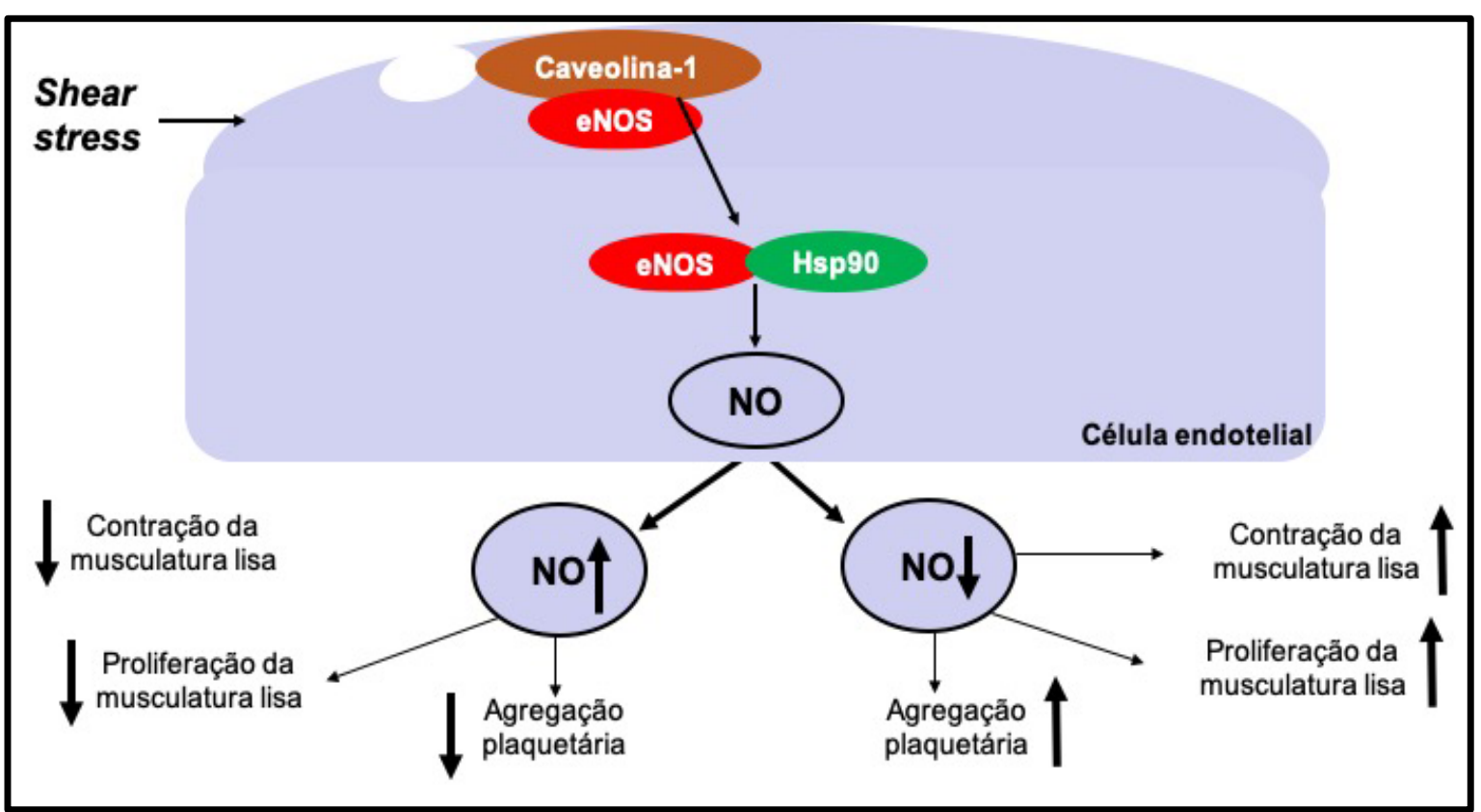

Figura 2- Esquema de produção de NO (Adaptado Vanhoutte PM et al Circulation Research 2016)(35)

Abreviaturas: $\mathrm{NO}=$ óxido nítrico/eNOS= óxido nítrico sintase endotelial/HSP90= Heat Shock Protein 90).

O pesquisador Ferruccio Ritossa, já revelara há mais de 50 anos, que algumas proteínas do citoplasma tinham aumentado sua expressão quando expostas ao calor ${ }^{(38)}$. Por esta resposta ao estímulo térmico, receberam o nome de proteínas de choque térmico $(\mathrm{HSP})^{(38)}$. Posteriormente foi demonstrado um papel importante das HSP no controle das funções celulares ${ }^{(39)}$. Dentre estas proteínas, a HSP70 apresenta grande potencial protetor contra a disfunção das células endoteliais, auxiliando o enovelamento proteico, inclusive de HSP90(40); ação que impede que proteínas malformadas se agreguem pois, além de inúteis, são potencialmente nocivas ${ }^{(41)}$. 
Atualmente, a HSP70 é considerada biomarcadora de progressão da doença aterosclerótica nos vasos sistêmicos, cujas oscilações de nível estariam relacionadas à progressão da doença ${ }^{(42)}$. Quando encontrada em alta quantidade, essa proteína parece proteger o sistema cardiovascular, pois desempenha um papel importante na inibição da disfunção endoteliall ${ }^{(43)}$. Da mesma família da HSP70, mas localizada no RE, existe a proteína GRP78. Em estudo sobre aterosclerose com modelo in vitro, níveis elevados demonstraram um papel funcional protetor para o vaso, com efeito antitrombótico, e de ativação de outras proteínas que participam da proteção vascular, como GRP94, envolvida na ativação da $\operatorname{eNOS}^{(44)}$.

As integrinas são responsáveis pela modulação, migração e manutenção das funções especificas das células e, recentemente, têm sido estudadas em busca de melhor entendimento fisiopatológico das doenças que envolvem processo inflamatório e câncer ${ }^{(45)}$. A alpha 5 integrina participa do processo de migração celular, e alterações em sua expressão podem estar relacionadas ao comprometimento da proteostase celular ${ }^{(45)}$. O shear stress pode regular sua expressão e favorecer a formação de trombos em placas de

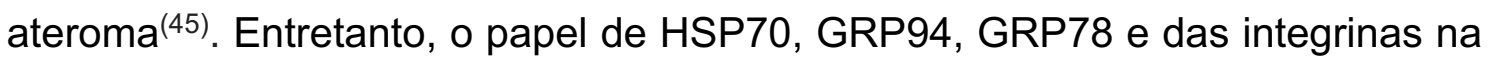
proteostase de células endoteliais pulmonares ainda é incerto.

Outra proteína expressa no RE é a dissulfeto isomerase proteica (PDI), que age na trombose, modulando fosfolípides da membrana de células endoteliais, importantes para a homeostase celular, e regula o início da coagulação( ${ }^{(46)}$.

Uma das funções do endotélio é promover a fibrinólise e, consequentemente, inibir a formação da trombose. Contribuindo para este efeito protetor existe a anexina A2 (A2), sintetizada no endotélio, cuja função é ativar o plasminogênio para liberação de plasmina (PN), responsável pela fibrinólise no vaso, e promove a resolução de trombos ${ }^{(47,48)}$. A translocação do complexo do citoplasma para o folheto externo da membrana da célula endotelial parece ser um passo regulatório importante na fibrinólise vascular, mas o mecanismo preciso é desconhecido. Este processo pode ocorrer em minutos ou horas 
quando o endotélio é exposto à hipóxia, choque térmico ou por ativação dos receptores de trombina ${ }^{(49)}$. Na Síndrome do Anticorpo Antifosfolípide (SAAF) existem anticorpos para $A 2$ e inibição da liberação da $P N$, com possível formação de trombos ${ }^{(50)}$. Existem estudos mostrando que o complexo A2 participa da hemostase $(48,51)$, e o estudo de sua liberação nos vasos pulmonares de portadores de HPTEC pode trazer informações que contribuam para a compreensão da fisiopatologia desta doença.

Na tabela 1 foi colocada a descrição resumida de algumas das proteínas envolvidas na proteostase vascular:

Tabela 1- Proteínas estudadas que participam da proteostase celular

\begin{tabular}{|c|c|c|}
\hline Proteína & Localização & Ação \\
\hline eNOS & Citoplasma & Enzima responsável pela produção de NO \\
\hline Caveolina-1 & Citoplasma & Liga-se a eNOS e inibe sua atividade \\
\hline $\begin{array}{l}\text { Alpha } 5 \\
\text { Integrina }\end{array}$ & Citoplasma & $\begin{array}{l}\text { Responsável pela modulação, migração e } \\
\text { manutenção de algumas funções celulares }\end{array}$ \\
\hline HSP90 & Citoplasma & $\begin{array}{c}\text { Responsável pela separação da caveolina-1 da eNOS } \\
\text { Adaptador para ativação da eNOS }\end{array}$ \\
\hline HSP70 & Citoplasma & $\begin{array}{l}\text { Altos níveis são protetores de disfunção endotelial } \\
\text { (ação anti-inflamatória na aterosclerose) }\end{array}$ \\
\hline Anexina A2 & Citoplasma & $\begin{array}{c}\text { Pertence ao complexo macromolecular que se liga à } \\
\text { plasmina - Papel na fibrinólise }\end{array}$ \\
\hline GRP78(BIP) & RE & $\begin{array}{l}\text { Família da HSP70/protetora de disfunção endotelial } \\
\qquad \text { Papel antitrombótico }\end{array}$ \\
\hline GRP94 & RE & Família da HSP90/Auxilia no enovelamento proteico \\
\hline PDI & RE & $\begin{array}{c}\text { Oxidação, redução, isomerização de ponte de sulfeto } \\
\text { Envolvida na fase inicial de formação do trombo }\end{array}$ \\
\hline
\end{tabular}

Abreviaturas: eNOS = óxido nítrico sintase endotelial / HSP = Heat Shock Protein/ GRP= proteína regulada pela glicose / BIP = binding immunoglobulin protein / $\mathrm{PDI}=$ dissulfeto isomerase proteica / $\mathrm{RE}=$ retículo endoplasmático. 


\section{Hipótese}

As células endoteliais da artéria pulmonar de pacientes com HPTEC apresentam disfunção endotelial e falha na proteostase, mais evidentes quando submetidas a estímulos, como o shear stress e hipóxia. 
2. Objetivos 
A. Caracterização morfológica das células em culturas provenientes de artéria pulmonar de pacientes com HPTEC submetidos à TEAP.

B. Avaliação da resposta das células endoteliais pulmonares, por meio da análise de proteínas envolvidas na proteostase celular, como eNOS, HSP90, HSP70, GRP78, GRP94, caveolina-1, alpha 5 integrina, PDI e anexina A2, em culturas submetidas a diferentes níveis de stress mecânico, à hipóxia e avaliação imuno-histoquímica da camada íntima do vaso pulmonar para HSP70 e anexina A2. 
3. Métodos 
O material extraído de sete pacientes submetidos à tromboendarterectomia no Instituto do Coração (InCor, Brasil) foi estudado de acordo com o protocolo aprovado pelo comitê de ética do Hospital das Clínicas da Faculdade de Medicina da Universidade de São Paulo (HCFMUSP) e Comissão para Análise de Projetos de Pesquisa (CAPPesq) sob o número 1.051.734 (Anexo A).

Pacientes em uso de medicação específica para HP ou que tinham SAAF foram excluídos. Nenhuma cultura usada para a realização dos ensaios foi maior que passagem 6, devido ao risco de mudança de resultados, decorrente do excessivo número de replicações. As características clínicas e hemodinâmicas pré-operatórias dos pacientes cujos trombos foram obtidos são mostradas na tabela 2.

Tabela 2- Dados clínicos e hemodinâmicos dos pacientes de quem os trombos foram extraídos $(n=7)$

\begin{tabular}{|l|c|}
\hline Idade (anos) & $57 \pm 13$ \\
\hline Sexo(homem:mulher) \% & $16: 84$ \\
\hline Classe funcional (1/2/3/4) \% & $0 / 34 / 16 / 50$ \\
\hline Débito cardiaco, L/min & $3.4 \pm 1.1$ \\
\hline PAPm, $\mathrm{mmHg}$ & $55 \pm 19$ \\
\hline RVP, dyn $\cdot \mathrm{s}^{-1} \cdot \mathrm{cm}^{-5}$ & $1.000 \pm 552$ \\
\hline
\end{tabular}

Abreviaturas: PAPm = Pressão de artéria pulmonar média / RVP: Resistência vascular pulmonar / L/min = Litros/minuto / dyn: dynes.

As peças cirúrgicas (Figura 3), provenientes das tromboendarterectomias pulmonares, foram colocadas imediatamente em um meio de transporte com soro fisiológico $0,9 \%$ gelado, misturado a penicilina ( $1 \%$ de concentração) e processadas em até uma hora após sua retirada. 


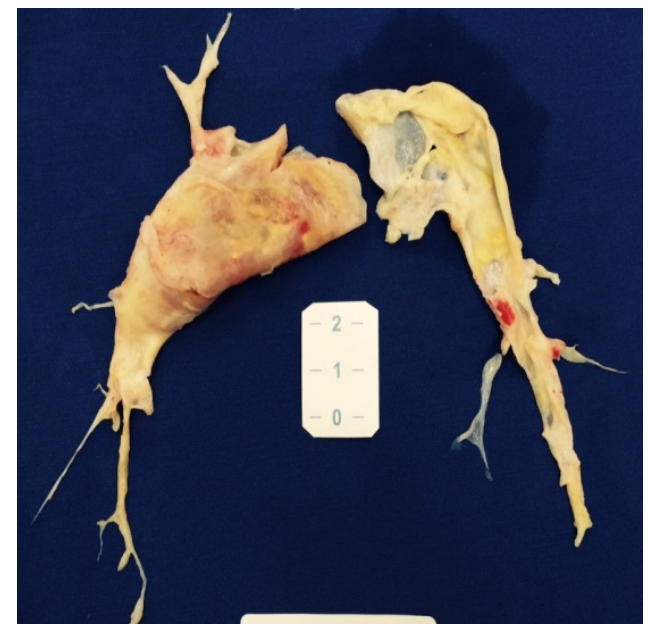

Figura 3- Espécime cirúrgico

\subsection{Culturas celulares}

\subsubsection{Células HPTEC}

\section{$\underline{\text { Cultura por meio de extração por colagenase (endoteliais) }}$}

Para o crescimento de células endoteliais, os tecidos foram cortados em $2 \mathrm{~cm} \times 2 \mathrm{~cm}$ e colocados em tubos cônicos de $15 \mathrm{~mL}$ com colagenase tipo II (worthington $®$ ). Permaneceram embebidos na colagenase $0,2 \%$ por quinze minutos, em temperatura ambiente ${ }^{(52)}$. Posteriormente, o sobrenadante (sem os tecidos) foi colocado em tubo cônico e centrifugado por cinco minutos, a uma temperatura de $4^{\circ} \mathrm{C}$, a $1.500 \mathrm{rpm}$. Este sobrenadante aspirado e o pellet suspenso em meio específico para células endoteliais, o EGM-2MV (Clonetics, Lonza®), colocados em garrafas de cultura de $25 \mathrm{~cm}^{2}$ (revestidas com gelatina $3 \%$ ) e incubados em $5 \% \mathrm{CO}_{2}, 100 \%$ de umidade e a $37{ }^{\circ} \mathrm{C}$ (Figura 4 ). O meio de cultura foi trocado pela primeira vez após três dias do procedimento e, em seguida, a cada quarenta e oito horas. Posteriormente foi realizada a ampliação das amostras para outras garrafas de $25 \mathrm{~cm}^{2}$ e congeladas na terceira passagem. 


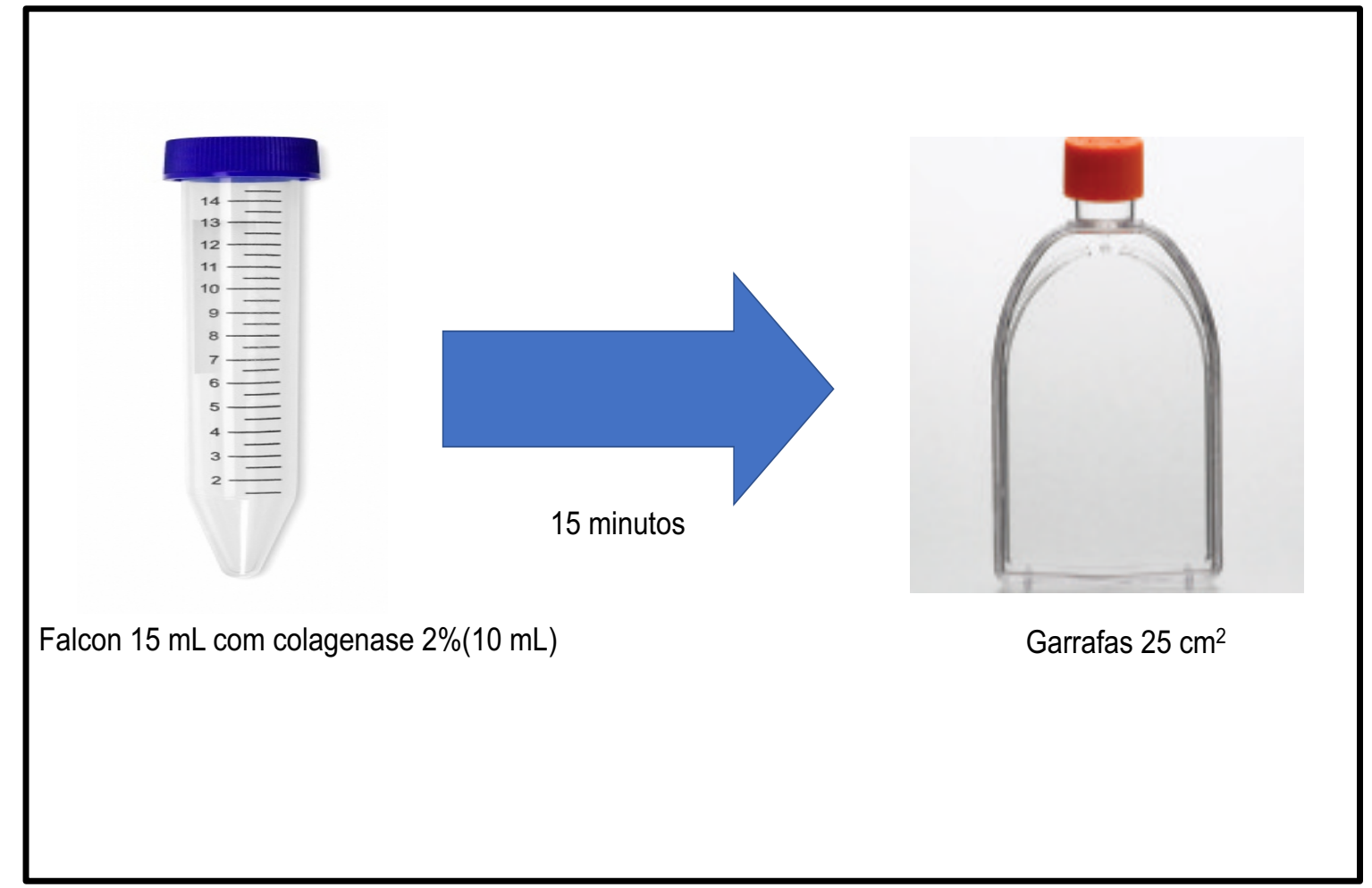

\section{Figura 4 - Método de extração por colagenase}

FONTE: https://www.ciencor.com.br/todos-os-produtos/1726-garrafa-p-cultura-corning25cm-tpa-plug-se-cx-500.html http://www.heathrowscientific.com/tubes-50ml-rack-25-rk-20rk-cs-i-hea4427r

\section{$\underline{\text { Cultura de células por explante (endoteliais e musculares) }}$}

Os tecidos foram cortados em $50 \mathrm{~mm} \times 50 \mathrm{~mm}$ e colocados em placas de seis poços (Figura 5) cuidadosamente, de modo que a parte interna da artéria ficasse voltada para o fundo da placa. Os poços foram revestidos com gelatina $3 \%$ para garantir que as células ficassem presas na placa. Para cada trombo retirado, foram utilizadas duas placas, uma para extração de células endoteliais, onde se utilizou o meio EGM-2MV (Clonetics, Lonza ${ }^{\circledR}$ ) com $5 \%$ de soro fetal bovino (SFB) e outra com meio de cultivo DMEM $^{\circledR}$ com $10 \%$ de SFB, para extração de células musculares. Com os tecidos depositados nas placas, algumas gotas do meio foram colocadas em cada fragmento. Posteriormente incubados em estufa com $5 \%$ de $\mathrm{CO} 2,100 \%$ de umidade e a $37{ }^{\circ} \mathrm{C}$. Após 24 horas do dia do processamento, o meio era trocado para 500 microlitros $(\mu \mathrm{l})$ e, 48 horas depois desta primeira troca, foi realizada uma nova com $1 \mathrm{~mL}$; a partir 
desta, sucederam-se a cada dois dias. Após um período que levou em média de 4 semanas a 6 semanas, as células que cresceram por meio deste método foram destacadas das placas com uso de tripsina $(0,375 \mathrm{mg} / \mathrm{mL})$, agrupando visualmente as células com mesma morfologia ao microscópio e colocadas em garrafas de $25 \mathrm{~cm}^{2}$ e, posteriormente, foi realizada a ampliação em garrafas de $25 \mathrm{~cm}^{2}$, de acordo com o crescimento celular.

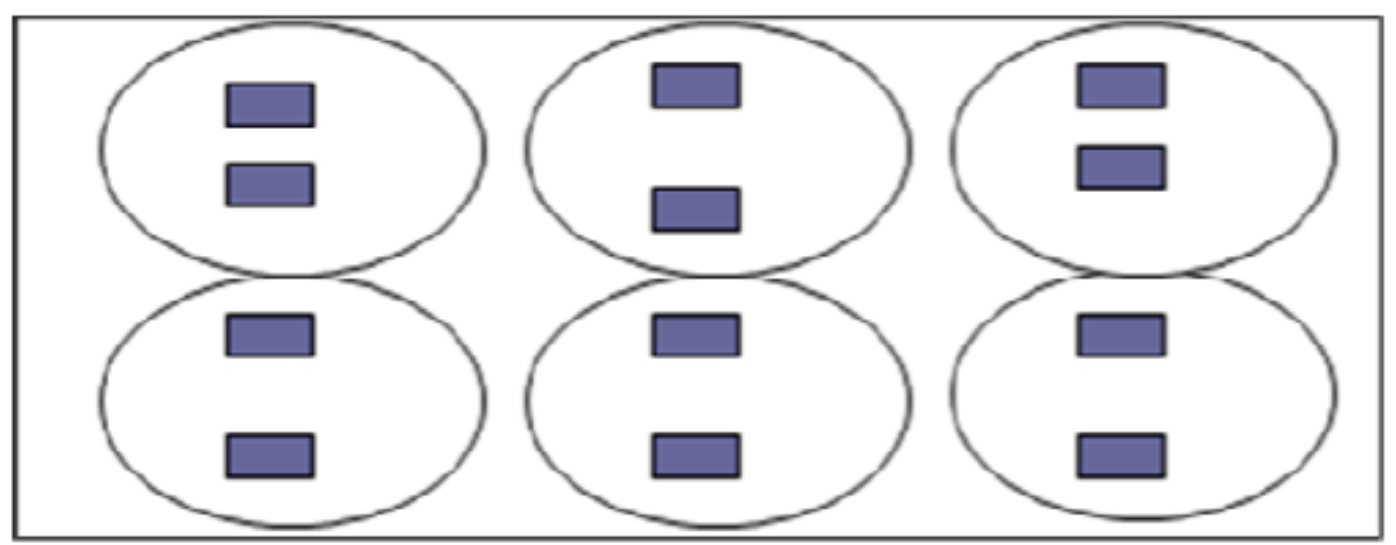

Figura 5 - Placa de seis poços com esquematização da colocação dos fragmentos do trombo

Após as ampliações das amostras, nos dois métodos de extração, as células foram congeladas, normalmente em passagem 3 de cultivo, com uso de meio de congelamento na seguinte proporção: meio sem SFB 50\%, SFB 45\%, dimetilsulfóxido ou sulfóxido de dimetilo (DMSO) $5 \%$; inicialmente foram colocadas em freezer $-80^{\circ} \mathrm{C}$ e, após vinte e quatro horas, armazenadas em nitrogênio líquido. Todas as amostras foram congeladas quando atingiram $80 \%$ de confluência.

\subsubsection{Células controle}

Como grupo controle foram utilizadas as células endoteliais pulmonares humanas de linhagem, criopreservada, catálogo C0085C (Lifetechnology ${ }^{\circledR}$ ). Estas foram cultivadas em garrafas de $25 \mathrm{~cm}^{2}$, submetidas aos mesmos protocolos e experimentos das células dos pacientes com HPTEC e usadas para comparação. 


\subsection{Marcações com anticorpos}

\subsubsection{Marcação das culturas}

Após o cultivo, as células com morfologia de endoteliais e as células endoteliais pulmonares humanas de linhagem foram marcadas com:

- anti-CD 31: específico para endotélio (BD ${ }^{\circledR}$ pharmingen, alexa fluor 647 , mouse anti-human CD31, cat number 558094).

- anti-CD90: marcador de células mesenquimais (Abcam ${ }^{\circledR}, \mathrm{PE}$, ab957000).

As células marcadas foram quantificadas pelo método de citometria de fluxo no citômetro BD Excalibur ${ }^{\circledR}$ (Figura 6). As células que foram extraídas dos trombos dos pacientes constituíram o grupo HPTEC e as controles, o grupo CE.

Figura 6 - Citômetro de fluxo (BD Excalibur ${ }^{\circledR}$ ).

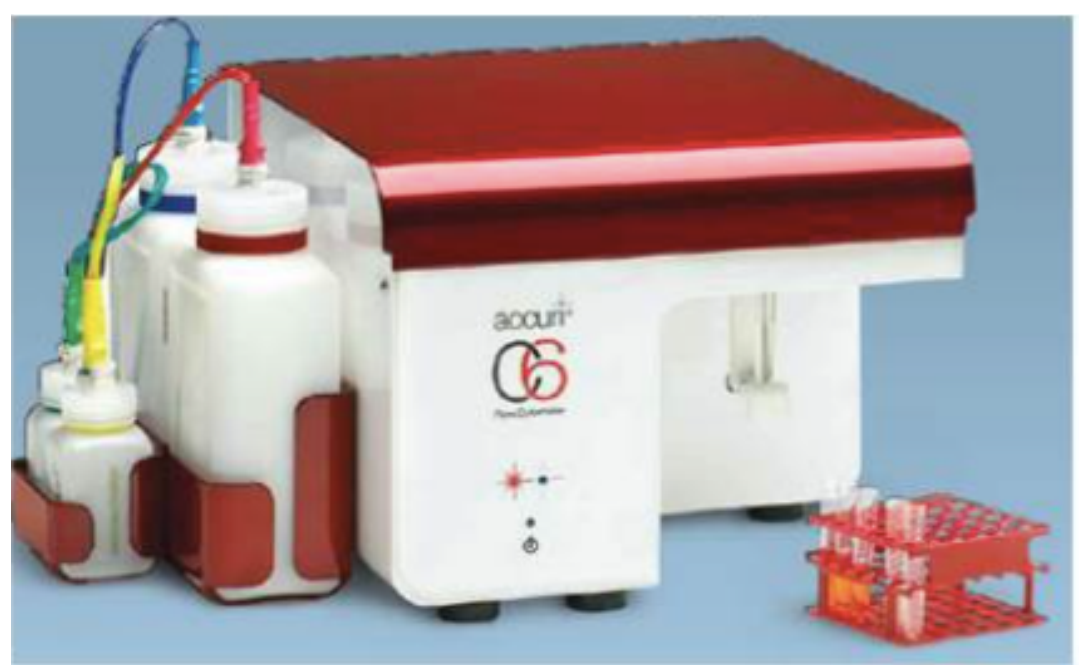

FONTE: $\underline{\text { http://www.bdbiosciences.com/br/documents/Aplicacoes Citometria.pdf }}$ 


\subsubsection{Imuno-histoquímica}

Foram realizadas marcações diretas no tecido dos trombos ${ }^{(53)}$ que estavam congelados em freezer numa temperatura de $-80^{\circ} \mathrm{C}$. Cortes histológicos de $3 \mathrm{~mm}$ de espessura contendo amostras representativas do endotélio extraído dos trombos de sete pacientes com HPTEC. Quatro artérias pulmonares de doadores de transplante de pulmões foram utilizadas como tecido controle. Todas as amostras foram submetidas à análise imuno-histoquímica para identificação de HSP70 (Abcam ${ }^{\circledR}$, anticorpo anti-Hsp70 (3A3), catálogo número ab5439) e anexina $2\left(\right.$ Abcam $^{\circledR}$, anticorpo C antianexina A2 C-terminal, catálogo número ab185957), de acordo com o protocolo do fabricante.

Histomorfometria: a quantificação histomorfométrica da expressão dos marcadores HSP70 e anexina A2 foi realizada por meio da análise de cinco campos diferentes, selecionados aleatoriamente em uma ampliação de 400 x, utilizando um analisador de imagem acoplado ao microscópio. O sistema consiste em uma câmera Olympus- $5^{\circledR}$ acoplada a um microscópio da mesma marca, a partir do qual as imagens são visualizadas no monitor e avaliadas em um sistema de imagem digital (Software Image Pro-Plus 6.0 ${ }^{\circledR}$ ). A área total do endotélio e a área do anticorpo marcado nos cinco campos diferentes de cada imagem foram usadas para mensurar a quantidade de marcador no tecido.

\subsection{Método de stress celular}

\subsubsection{Shear stress}

Os experimentos foram realizados em uma placa $\mathrm{p} 100\left(\mathrm{BD}^{\circledR}\right)$ e aparelho de shear stress que consiste em um modelo cone e placa. Este aparelho (Figura 7) é mantido em uma atmosfera a 5\% CO2 e 50\% ar umidificado, a uma 
temperatura de $37^{\circ} \mathrm{C}$. O fluxo laminar foi mantido em 5 dynes $/ \mathrm{cm}^{2}$ e 15 dynes $/ \mathrm{cm}^{2}$ por vinte e quatro horas ${ }^{(54)}$. Além da placa submetida ao shear, foi colocada sempre uma outra, na condição estática, utilizada para comparação.

Figura 7- Aparelho de shear stress modelo cone-placa

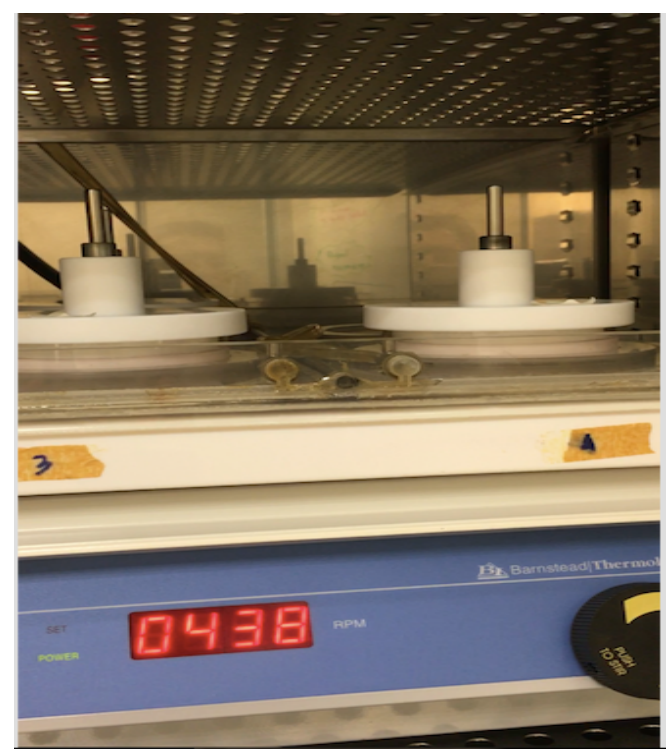

Na Figura 8 podemos observar o desenho do protocolo de shear stress.

Figura 8 - Protocolo de shear stress

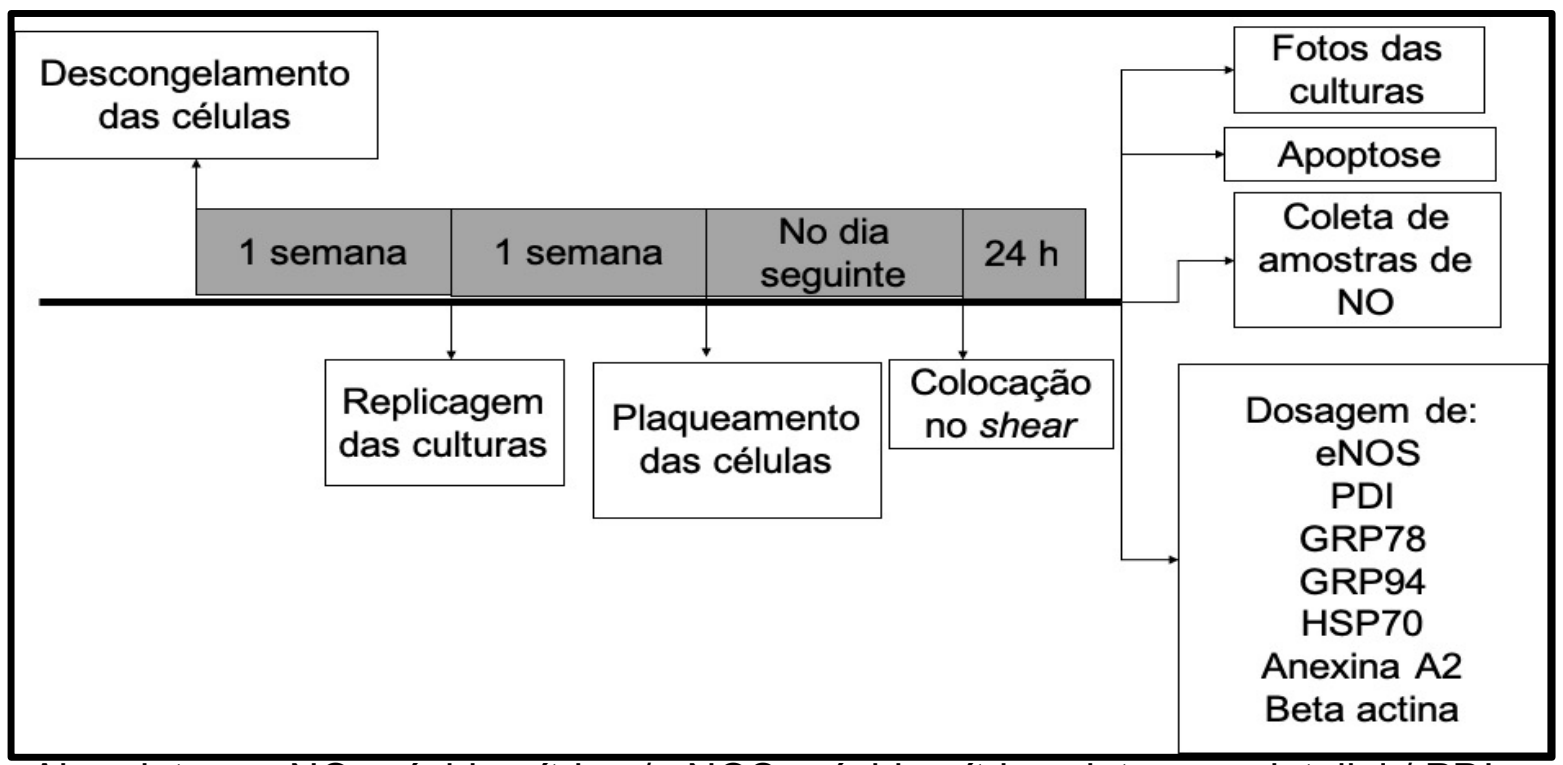

Abreviaturas: $\mathrm{NO}=$ óxido nítrico / eNOS = óxido nítrico sintase endotelial / PDI = dissulfeto isomerase proteica / GRP78 $=$ Glucose-regulated protein $78 /$ GRP94 = Glucose-regulated protein 94 / HSP70 = Heat Shock Protein 70. 
Todos os experimentos foram feitos em duplicata, sendo que em um dia foi realizada a velocidade de 438 rotações por minuto, que equivale a 15 dynes $/ \mathrm{cm}^{2}$ e, no outro dia, a velocidade de $146 \mathrm{rpm}$, que corresponde a 5 dynes $/ \mathrm{cm}^{2}$. A determinação da velocidade de rotação em rpm foi feita pelo cálculo do ângulo entre o cone e a placa de cultura.

Após este procedimento foram realizados:

- Fotos das placas

- O sobrenadante foi colocado em tubo cônico de $15 \mathrm{ml}$, centrifugado a 1.500 rpm por cinco minutos. A seguir; foram separados $4 \mathrm{~mL}$ e distribuídos em quatro eppendor ${ }^{\circledR}$, posteriormente estocados no freezer $-80^{\circ} \mathrm{C}$ para dosagem de nitrito, realizada a partir da avaliação inicial de oito concentrações para definir a curva padrão. Depois, foram efetuadas diluições da solução em concentrações de 00,5 uM a 20 uM, possibilitando medidas de 40 amostras num mesmo experimento pelo NO Analyzer modelo 280 , Sievers ${ }^{\circledR}$.

- Apoptose: foi analisado o marcador anexina $V\left(\right.$ Roche $\left.^{\circledR}\right)$, que avalia a morte celular recente. As culturas foram retiradas das placas e colocadas em tubo cônico de $15 \mathrm{~mL}$, centrifugadas a $1.500 \mathrm{rpm}$ por cinco minutos, feitas lavagens com buffer específico e colocadas em seis tubos para citometria, com $20 \times 10^{4}$ células por tubo. Posteriormente ficaram incubadas por quinze minutos em temperatura ambiente com $5 \mu \mathrm{L}$ de marcador, de acordo com o protocolo do fabricante. Em sequência as amostras foram analisadas em citômetro de fluxo (BD Excalibur®), limitadas a 10.000 eventos por tubo.

- Preparação dos lisados e avaliação da expressão proteica por Western-blot: as células foram lavadas uma vez com o meio de cultura Roswell Park Memorial Institute $\left(\mathrm{RPMI}^{\circledR}\right)$, tratadas com tripsina e, após se destacarem da placa, ressuspendidas em meio RPMI com 10\% de SFB (3mL). As placas foram lavadas duas vezes com 4mL RPMI, com 10\% de SFB, para garantir que todas as células fossem removidas. Depois da homogeneização, metade das células seguiu para avaliação de morte celular e a outra metade foi lavada uma vez com phosphate buffered saline (PBS) no volume de $6 \mathrm{~mL}$. Após a centrifugação a 
1.500rpm por 5 min a $10^{\circ} \mathrm{C}$, o sobrenadante foi descartado e as células, lisadas em 200uL de tampão de lise A (Hepes 20mM, NaCl 150mM, glicerol 10\%, Triton

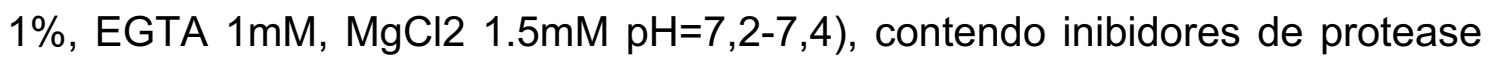
([leupeptina $(1 \mu \mathrm{g} / \mathrm{mL})$, aprotinina $(1 \mu \mathrm{g} / \mathrm{mL})$, PMSF (phenylmethanesulfonylfluoride, $1 \mathrm{mM}$ )] ) por $30 \mathrm{~min}$ a $4^{\circ} \mathrm{C}$. Os lisados foram ao sonicador por 6 min e centrifugados a $12.000 \mathrm{rpm}$ por $10 \mathrm{~min}$ a $4^{\circ} \mathrm{C}$. O sobrenadante foi estocado a $-80^{\circ} \mathrm{C}$ até o uso. O lisado contendo $40 \mu \mathrm{g}-60 \mu \mathrm{g}$ de proteína foi incubado com tampão de amostra contendo $\beta$-mercaptoentanol por 30 min a $25^{\circ} \mathrm{C}$ e depois fervido por cinco min. As amostras foram submetidas a eletroforese em gel de poliacrilamida $10 \%(30 \mathrm{~mA} / \mathrm{gel}$ por1h30). As proteínas foram transferidas para membrana de nitrocelulose (100mA por 1h) por sistema úmido, seguido de bloqueio da membrana por $1 \mathrm{~h}$ com $5 \%$ de leite desnatado. As membranas foram incubadas a $4^{\circ} \mathrm{C}$ por $15 \mathrm{~h}$ a $18 \mathrm{~h}$ com os anticorpos primários e, em seguida, lavadas três vezes com TBS-T (Tris $10 \mathrm{mM}, \mathrm{NaCl} 150 \mathrm{mM}$, tween 0,1\%) e incubadas com o anticorpo fluorescente donkey anti-mouse, anti-rabbit ou antigoat IRDyeR $800 \mathrm{CW}$ por $1 \mathrm{~h}$ sob agitação a $25^{\circ} \mathrm{C}$. Após três lavagens com TBS$\mathrm{T}$, procedeu-se à revelação no equipamento Odyssey ${ }^{\circledR}$ (LI-COR). As análises e quantificação das bandas foram feitas, utilizando o programa do LICOR. Os anticorpos foram diluídos em TBST 1:1.000-1:5.000: anti-eNOS (610297, BD ${ }^{\circledR}$ ), anti-PDI (RL90, Thermo scientific $\left.{ }^{\circledR}\right)$, anti-GRP78 (ab21685, Abcam ${ }^{\circledR}$ ), antiGRP94 (ab52031, abcam $\left.^{\circledR}\right)$, anti-HSP70 (3A3, Abcam $\left.{ }^{\circledR}\right)$, antianexina A2 $\left(\right.$ ab185957, abcam $^{\circledR}$ ) e antibeta actina (AC-74, Sigma ${ }^{\circledR}$ ).

\subsubsection{Hipóxia}

As células foram submetidas a hipóxia (Figura 9), colocadas em uma câmara que simula um meio sem oxigênio, dentro de uma estufa (Figura 10), com $5 \%$ de $\mathrm{CO}_{2}$ e $1 \%$ de $\mathrm{O}_{2}$ (Figura 11). As culturas com confluência maior que $80 \%$ foram colocadas na estufa por períodos de vinte e quatro horas ${ }^{(54)}$. 


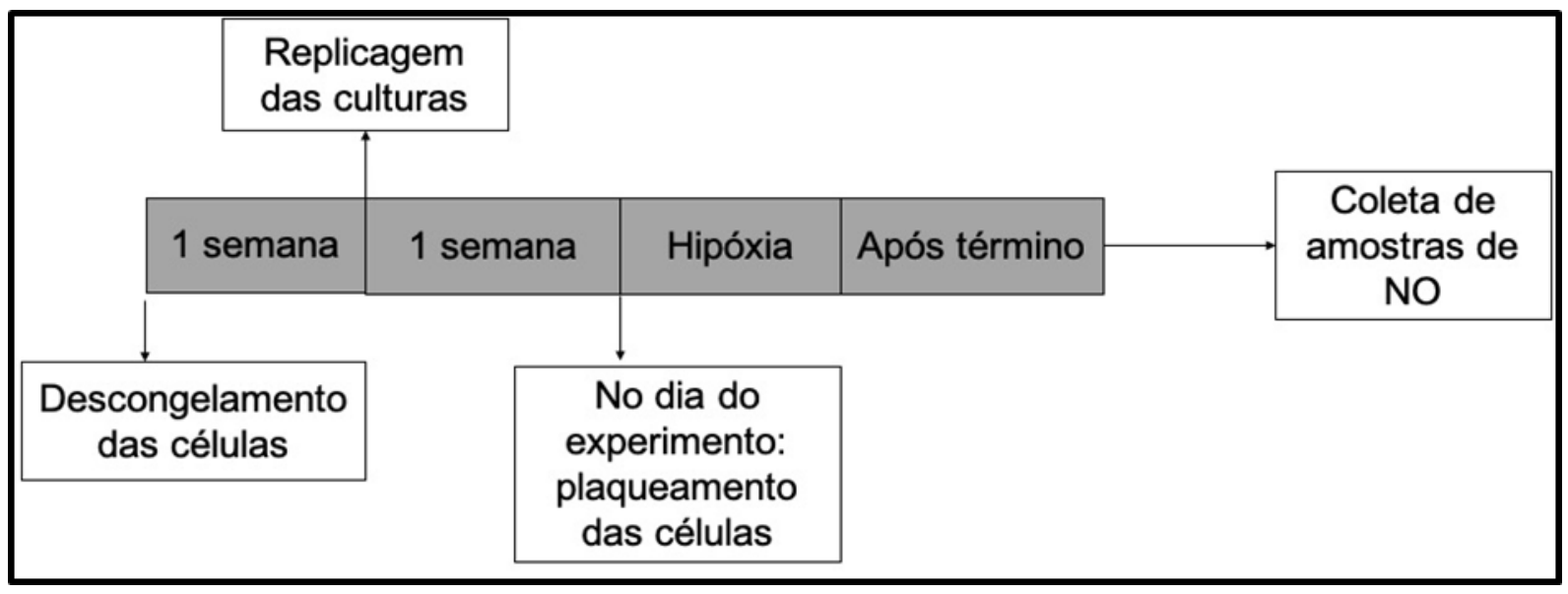

Figura 9 - Protocolo de hipóxia

Abreviaturas: $\mathrm{NO}=$ óxido nítrico

Figura 10 - Câmara de hipóxia
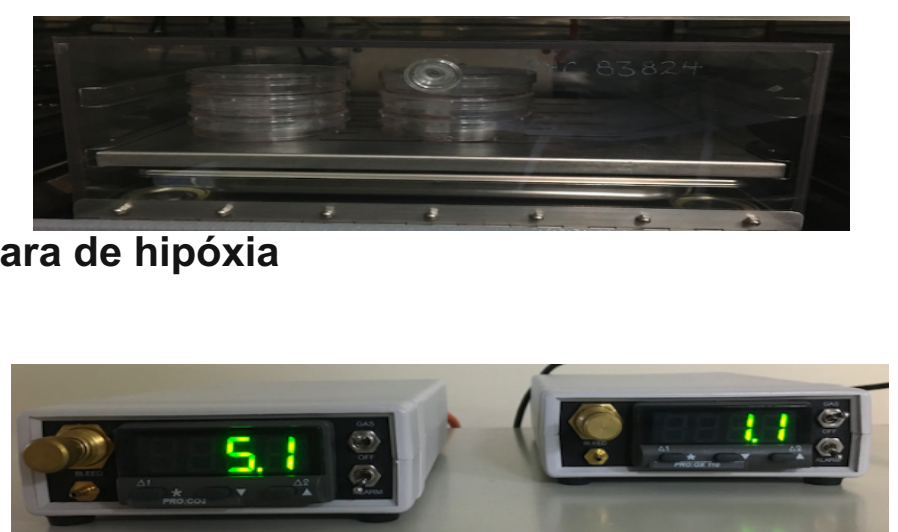

Figura 11- Controladores de $\mathrm{CO}_{2}$ e $\mathrm{O}_{2}$, respectivamente $5 \%$ e $1 \%$

\subsection{Análise estatística}

Utilizado o software GraphPad Prism 5.0, foram realizados: análise de variância de uma via (ANOVA) com teste pós-teste Newman-Keuls, para comparações entre três ou mais grupos; teste t pareado, para as comparações entre dois dados na mesma amostra. Em ambos os casos, o nível de significância foi 0,05 . 
4. Resultados 


\subsection{Culturas extraídas dos trombos}

Nas extrações foram obtidas células com morfologia de endoteliais e miofibroblasto (Figura 12).

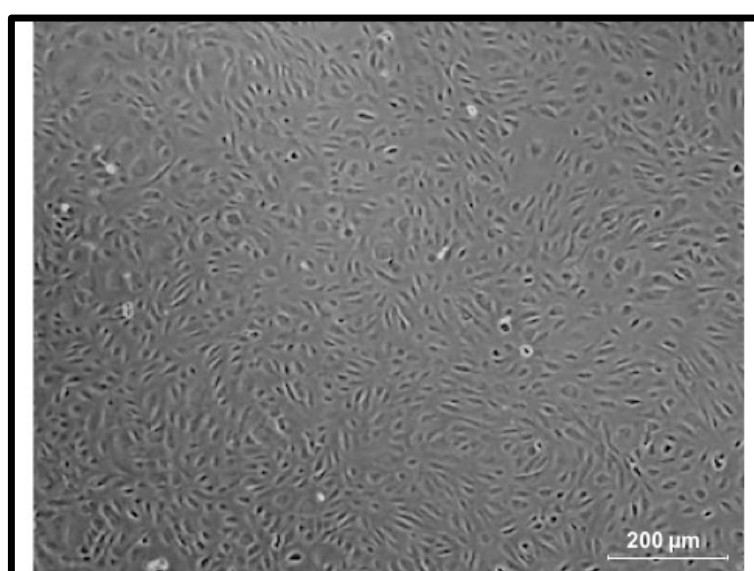

Células endoteliais extraídas dos trombos

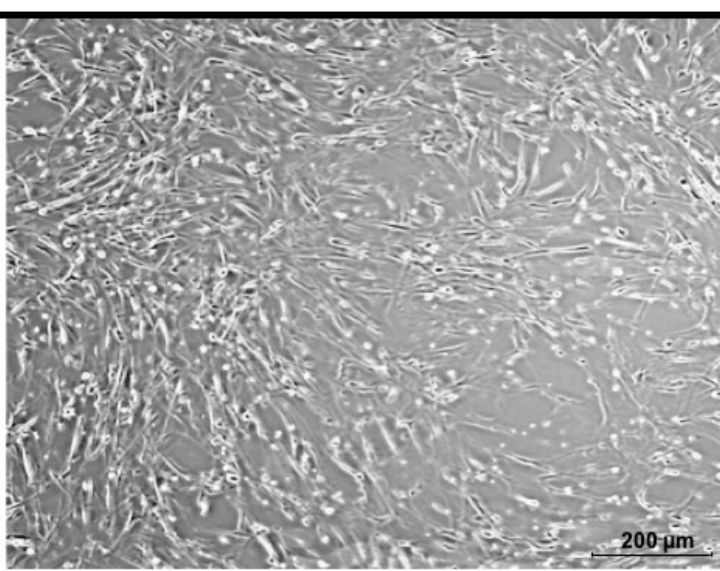

Miofibroblastos extraídos dos trombos

Figura 12- Fotos das culturas das células extraídas dos trombos

Na Figura 13 observam-se as fotos das culturas de dois pacientes do grupo HPTEC e do controle (CE).

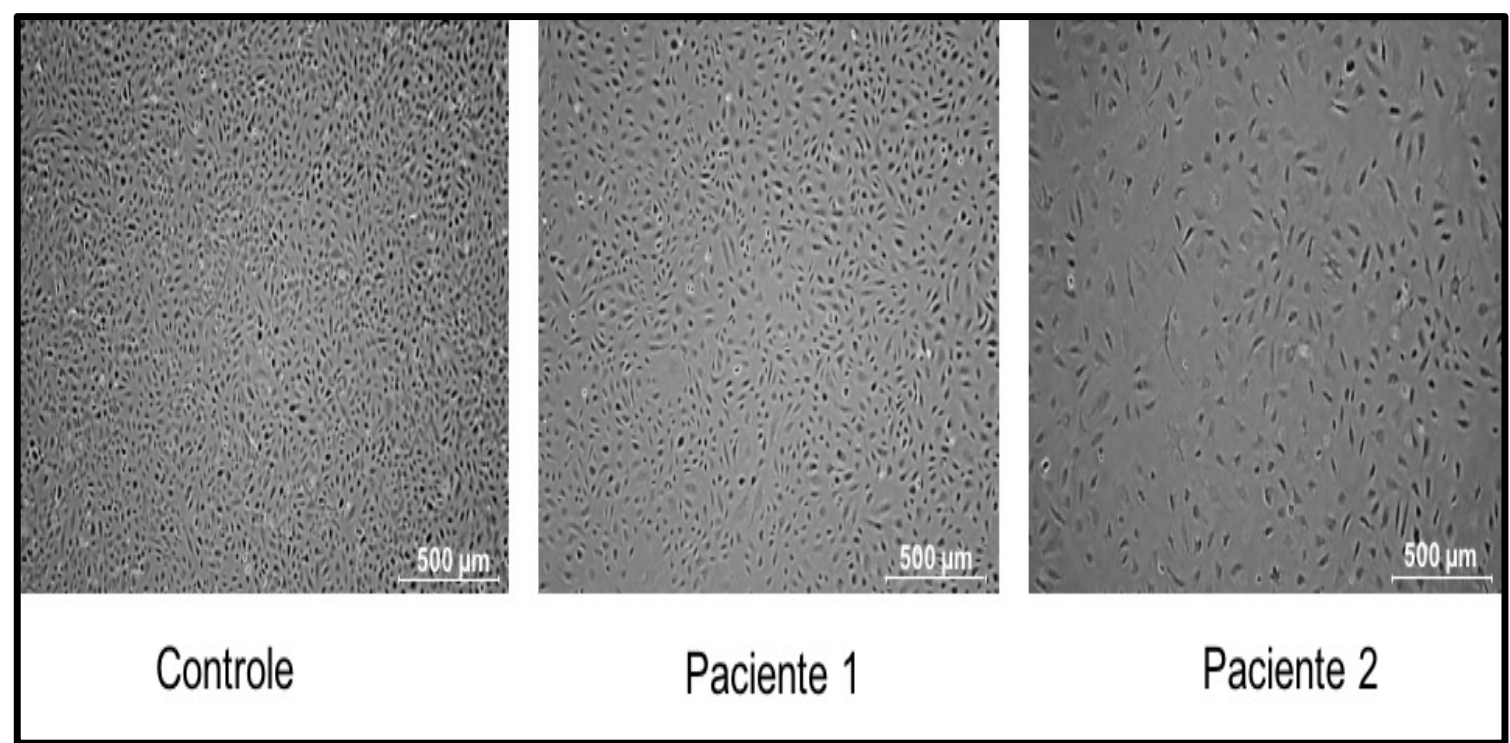

Figura 13- Fotos das culturas de dois pacientes com HPTEC e CE 


\subsection{Marcação das culturas}

Foram realizados experimentos de marcação nas culturas de células de artérias pulmonares de pacientes com HPTEC, analisadas posteriormente em citometria de fluxo. Ocorreu marcação com CD31 em 99,7\% das culturas e CD90 em menos de $1 \%$.

Na Figura 14 nota-se que a marcação do grupo HPTEC foi a mesma que a de CE.

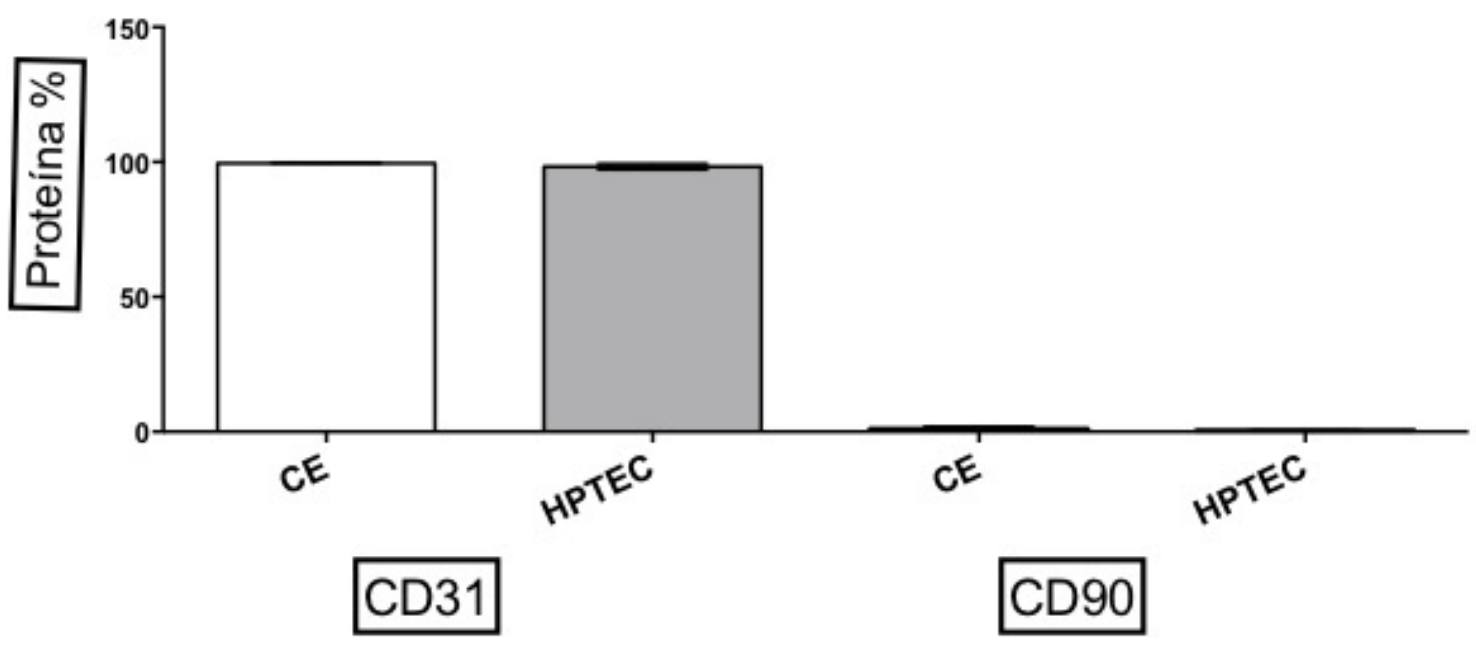

Figura 14- Marcação de CD31e CD90, analisadas em citometria de fluxo Abreviaturas: $\mathrm{CE}=$ células endoteliais / HPTEC = hipertensão pulmonar tromboembólica crônica / CD31 = cluster de diferenciação 31 / CD90 = cluster de diferenciação 90.

\subsection{Experimentos com shear stress}

$\mathrm{Na}$ comparação entre a condição estática (ausência de fluxo) e a condição que simula o alto fluxo, shear stress de 15 dynes $/ \mathrm{cm}^{2}$, observa-se um alinhamento das células nas culturas dos pacientes portadores de HPTEC e do controle (Figura15). No fluxo de 5 dynes $/ \mathrm{cm}^{2}$ não se verifica esse comportamento em nenhuma das culturas. Todas as fotos foram tiradas após vinte e quatro horas de shear (Figura 15). 


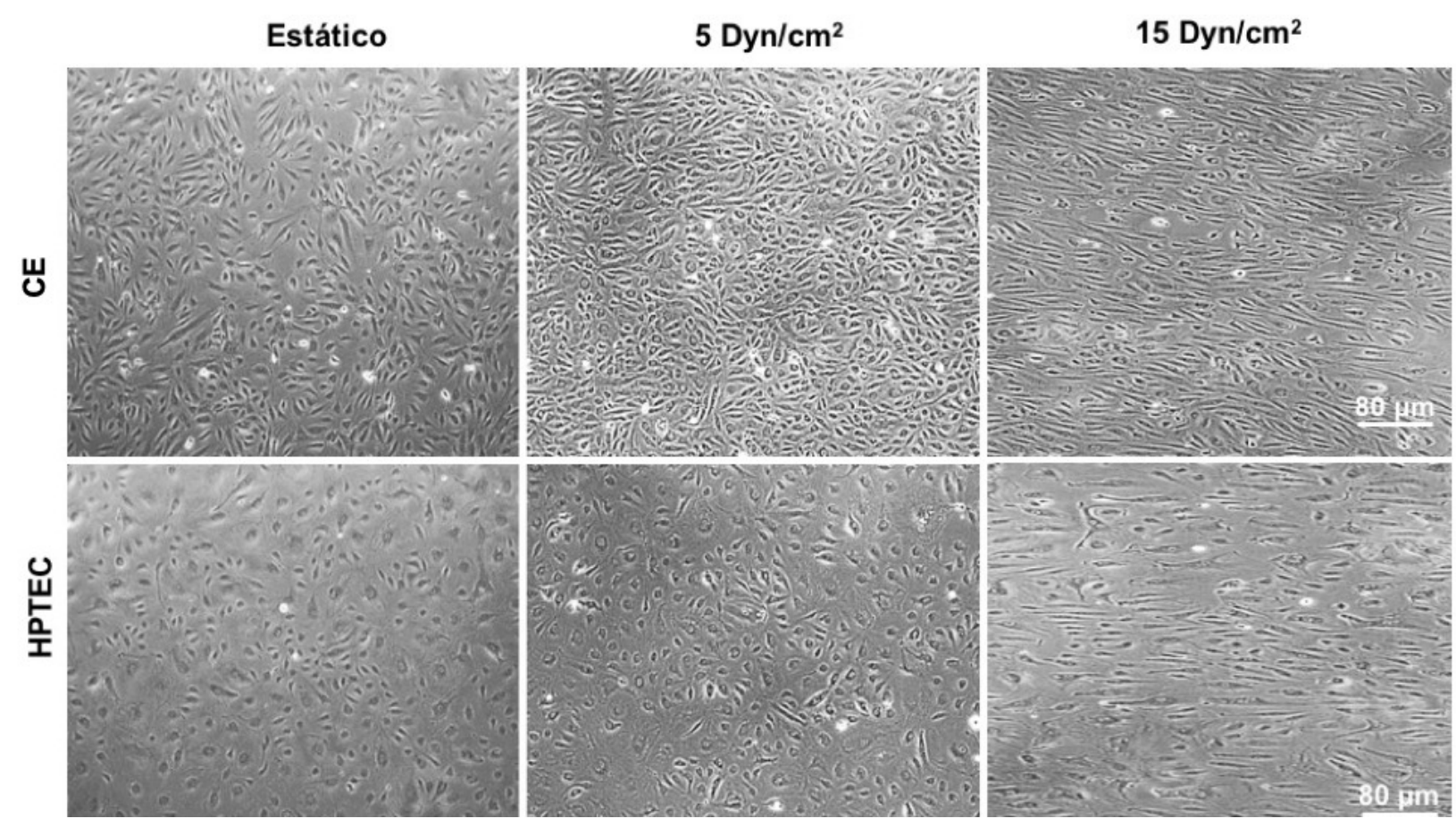

Figura 15- Foto com morfologia dos grupos CE e HPTEC (condições: estática, 5 dynes $/ \mathrm{cm}^{2}$, sem alinhamento e shear 15 dynes $/ \mathrm{cm}^{2}$, com alinhamento ao fluxo)

Abreviaturas: $\mathrm{CE}=$ células endoteliais $/ \mathrm{HPTEC}=$ hipertensão pulmonar tromboembólica crônica.

A Figura 16 mostra os resultados da quantificação intracelular da proteína eNOS, do nitrito no meio condicionado e de anexina $\mathrm{V}$. Na condição estática há uma diferença de $50 \%$ na expressão de eNOS no grupo HPTEC (Figuras 16 A e B). No controle houve elevação significativa dos níveis desta proteína após shear stress de alto fluxo laminar. Nas células HPTEC a expressão da eNOS elevou-se na condição de baixa e alta magnitude. No entanto, quando analisamos a resposta de HPTEC 15 comparada à do controle submetido à mesma condição, evidencia-se menor expressão dessa proteína. Na dosagem de nitrito (Figura $16 \mathrm{C}$ ), observaram-se valores menores nas células HPTEC na condição estática. Quando submetidos a estímulo, os dois grupos aumentaram as expressões. $\mathrm{Na}$ análise de morte celular por anexina $\mathrm{V}$ (Figura $16 \mathrm{D}$ ), não ocorreram diferenças. 
A

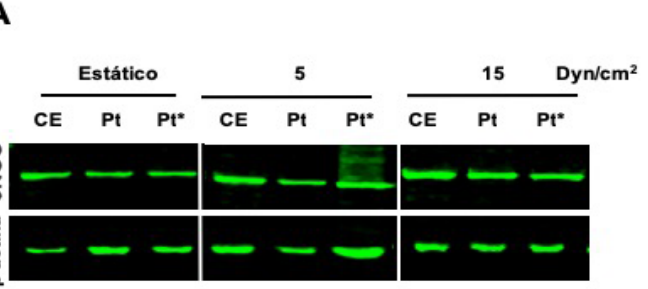

C

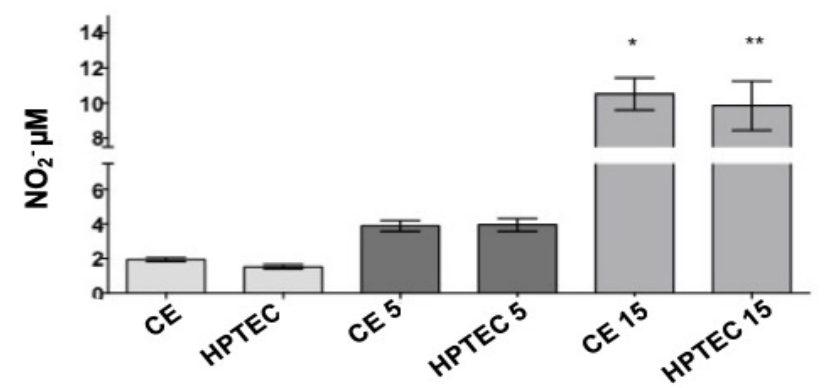

B

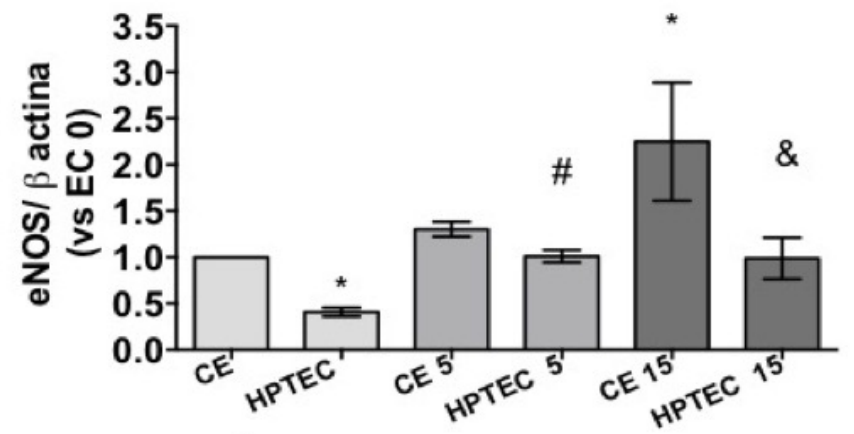

D

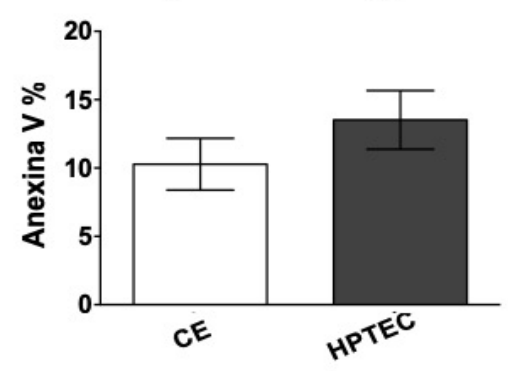

Figura 16- Efeito do shear stress na expressão proteica de eNOS, produção de NO e na morte celular

(A) Quantificação de eNOS intracelular e normalizada por ß-actina, por western blot, nas condições: estática, shear stress 5 dynes $/ \mathrm{cm}^{2}$ e 15 dynes $/ \mathrm{cm}^{2}$ durante vinte e quatro horas.

(B) Quantificação de eNOS, colunas representam a média \pm erro padrão $(n=7)$

(*) CE vs CE 15 e CE vs HPTEC (\#) HPTEC 5 vs CE 15 (\&) CE 15 vs HPTEC $15 p<0,05$ (ANOVA com pós-teste Newman-keuls).

(C) Produção de nitrito ( $\mathrm{NO}^{2-} \mathrm{uM}$ ), nas condições: estática, shear stress 5 dynes $/ \mathrm{cm}^{2} \mathrm{e}$ 15 dynes $/ \mathrm{cm}^{2}$ durante vinte e quatro horas $(\mathrm{n}=7)$

(*) CE vs CE 15 / HPTEC vs HPTEC $15 p<0,05$ (ANOVA com pós-teste Newman-keuls).

(D) Quantificação de anexina $\vee$ das culturas CE e HPTEC na condição estática. Não ocorreram diferenças na morte celular, nos dois grupos.

Abreviaturas: $\mathrm{NO}^{2-} \mathrm{UM}=$ dosagem de nitrito $/ \mathrm{CE}=$ células endoteliais na ausência de fluxo/HPTEC = hipertensão pulmonar tromboembólica crônica ausência de fluxo/CE 5 = células endoteliais expostas a 5 dynes $/ \mathrm{cm}^{2}$ HPTEC 5 = células do grupo hipertensão pulmonar tromboembólica crônica expostas a $5 \mathrm{dynes} / \mathrm{cm}^{2} / \mathrm{CE} 15=$ células endoteliais expostas a 15 dynes $/ \mathrm{cm}^{2} / \mathrm{HPTEC} 15$ = células do grupo hipertensão pulmonar tromboembólica crônica expostas a 15 dynes $/ \mathrm{cm}^{2}$. 
Para melhor entendimento da expressão de eNOS foram analisadas algumas das etapas de sua ativação, a partir da avaliação de caveolina 1. Analisada somente na condição estática, não houve diferenças entre ela e as células controle (Figura $17 \mathrm{~A}$ ). Ainda nesta avaliação da eNOS, foi estudada a expressão de HSP90 e Alpha 5 integrina (Figura 17 B). Ocorreu uma diferença significativa na expressão de HSP90 e nenhuma diferença em Alpha 5 integrina (Figura $17 \mathrm{~B}$ ).

A
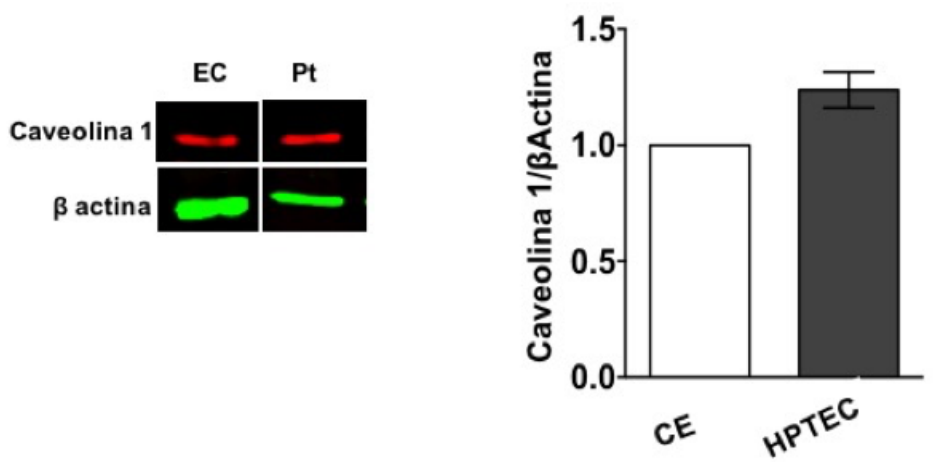

B
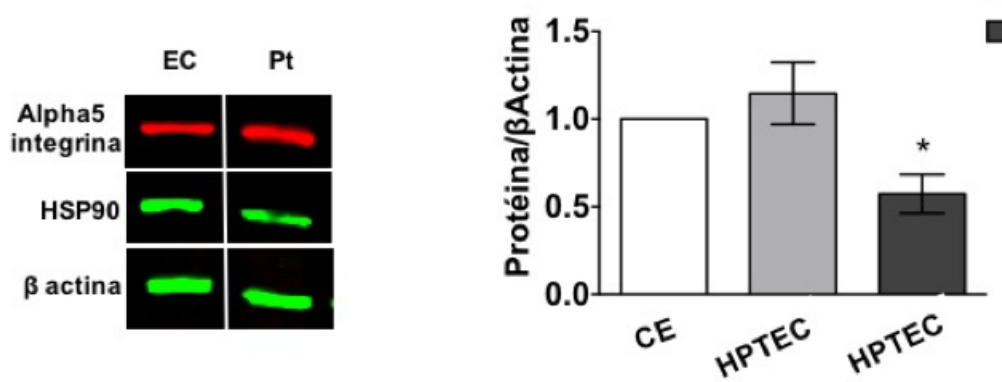

$\square$ Alpha 5 intergrina

$\square$ HSP9O

\section{Figura 17- Expressão de caveolina 1, Alpha 5 integrina e HSP90 na condição estática}

(A) Quantificação de caveolina 1 intracelular e normalizada por ß-actina, por meio de western blot e colunas representam a média \pm erro padrão $(n=6)$.

(B) Quantificação de Alpha 5 integrina e HSP90, normalizadas por ß-actina, por meio de western blot e colunas representam a média \pm erro padrão $(n=6)$.

${ }^{*}$ ) CE vs HPTEC $p<0,05$ (ANOVA com pós-teste Newman-keuls).

Abreviaturas: HSP90 = Heat Shock Protein 90/CE = células endoteliais na ausência de fluxo/HPTEC = hipertensão pulmonar tromboembólica crônica ausência de fluxo. 
Na avaliação da proteína GRP94 (Figura 18), envolvida no processo de ativação da eNOS, a quantificação intracelular na condição estática do grupo HPTEC foi $50 \%$ menor quando comparado ao controle. No shear as células do grupo HPTEC 15 e 5 respondem com valores menores do que as células do controle. Na comparação entre os grupos CE 15 e HPTEC 15, a expressão foi menor nas culturas dos pacientes.

A

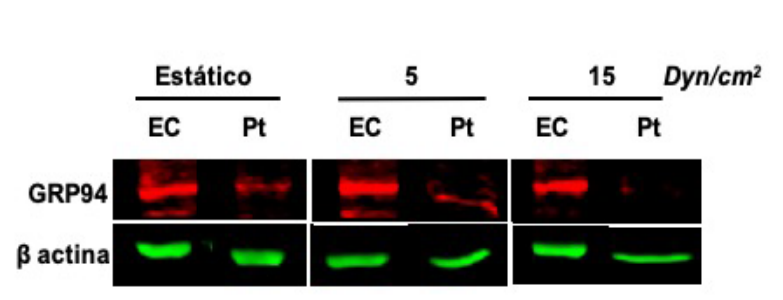

B

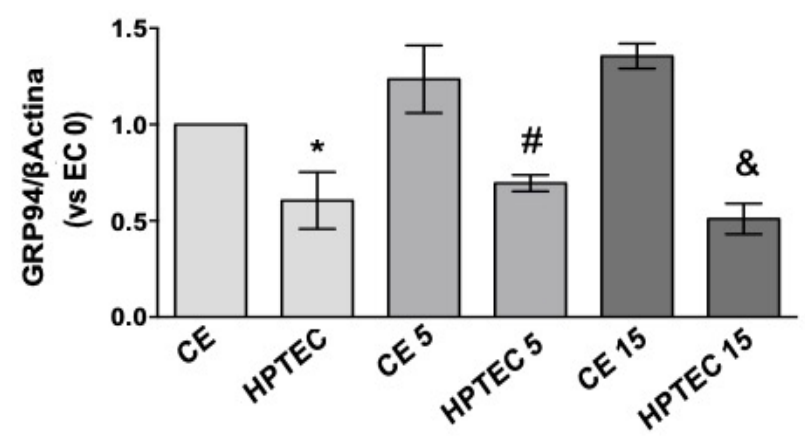

Figura 18- Efeito do shear stress na expressão proteica de GRP94

(A) Quantificação de GRP94 intracelular e normalizada por ß-actina, por meio de western blot, nas condições: estática, shear stress 5 dynes $/ \mathrm{cm}^{2}$ e 15 dynes $/ \mathrm{cm}^{2}$ durante vinte e quatro horas.

(B) Quantificação de GRP94, colunas representam a média \pm erro padrão $(n=7)$

$\left({ }^{*}\right)$ CE vs HPTEC (\#) HPTEC 5 vs CE 15 (\&) CE 15 vs HPTEC $15 p<0,05$ (ANOVA com pós-teste Newman-keuls).

Abreviaturas: GRP94 = Glucose-regulated protein 94/CE = células endoteliais na ausência de fluxo/HPTEC = hipertensão pulmonar tromboembólica crônica ausência de fluxo/CE 5 = células endoteliais expostas a 5 dynes $/ \mathrm{cm}^{2} /$ HPTEC 5 = células do grupo hipertensão pulmonar tromboembólica crônica expostas a 5 dynes $/ \mathrm{cm}^{2} / \mathrm{CE} 15=$ células endoteliais expostas a 15 dynes/ $\mathrm{cm}^{2}$ / HPTEC 15 = células do grupo hipertensão pulmonar tromboembólica crônica expostas a 15 dynes $/ \mathrm{cm}^{2}$. 
Na quantificação intracelular de GRP78 (Figuras 19 A e B), nota-se na condição estática uma tendência de diminuição no grupo HPTEC quando comparada ao controle. No shear de baixa magnitude, os níveis foram semelhantes nos dois grupos. Entretanto, na condição que simula o alto fluxo, a quantificação foi menor quando comparada às células do controle (CE 15). Na expressão de PDI (Figura 19 A e C) não houve diferença em nenhuma das condições.

B
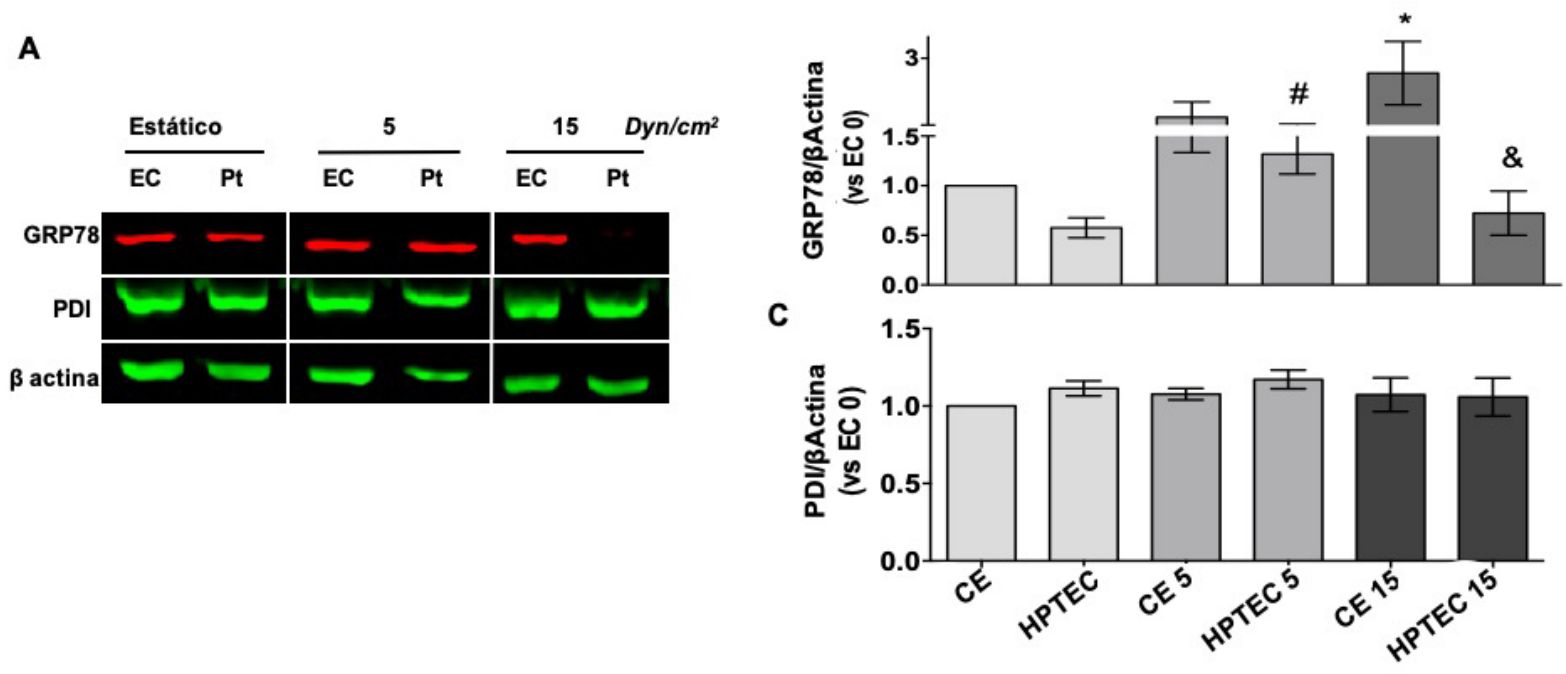

Figura 19- Efeito do shear stress na expressão proteica de GRP78(BIP) e PDI

(A) Quantificação de GRP78 e PDI intracelular e normalizada por ß-actina, por western blot, nas condições: estática, shear stress 5 dynes $/ \mathrm{cm}^{2}$ e 15 dynes $/ \mathrm{cm}^{2}$ durante vinte e quatro horas.

(B) Quantificação de GRP78, colunas representam a média \pm erro padrão $(n=7)$

$\left(^{*}\right)$ CE vs CE 15 (\#) HPTEC 5 vs CE 15 (\&) CE 15 vs HPTEC $15 p<0,05$ (ANOVA com pós-teste Newman-keuls).

(C) Quantificação de PDI intracelular/ß-actina nenhuma diferença foi encontrada.

Abreviaturas: GRP78 = Glucose-regulated protein 78/PDI $=$ Dissulfeto isomerase proteica/CE = células endoteliais na ausência de fluxo/HPTEC $=$ hipertensão pulmonar tromboembólica crônica ausência de fluxo/CE 5 = células endoteliais expostas a 5 dynes/ $\mathrm{cm}^{2} /$ HPTEC 5 = células do grupo hipertensão pulmonar tromboembólica crônica expostas a $5 \mathrm{dynes} / \mathrm{cm}^{2} / \mathrm{CE} 15$ = células endoteliais expostas a $15 \mathrm{dynes} / \mathrm{cm}^{2} / \mathrm{HPTEC}$ 15 = células do grupo hipertensão pulmonar tromboembólica crônica expostas a 15 dynes/ $/ \mathrm{cm}^{2}$. 
$\mathrm{Na}$ avaliação de HSP70 intracelular (Figura 20 A e B), na condição estática, a expressão está diminuída nas células do grupo HPTEC. No shear de alto e baixo fluxo, a quantificação nas células dos pacientes (HPTEC 15 e 5) foi menor que na do controle (CE 15 e 5). Na análise somente das células dos pacientes, no fluxo de alta magnitude, a expressão foi menor ainda.

A
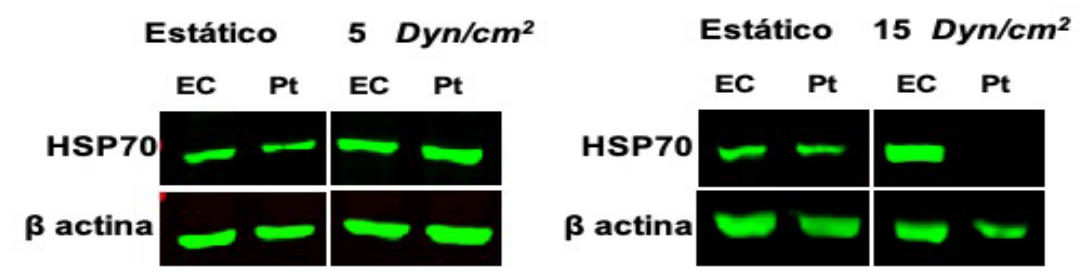

B

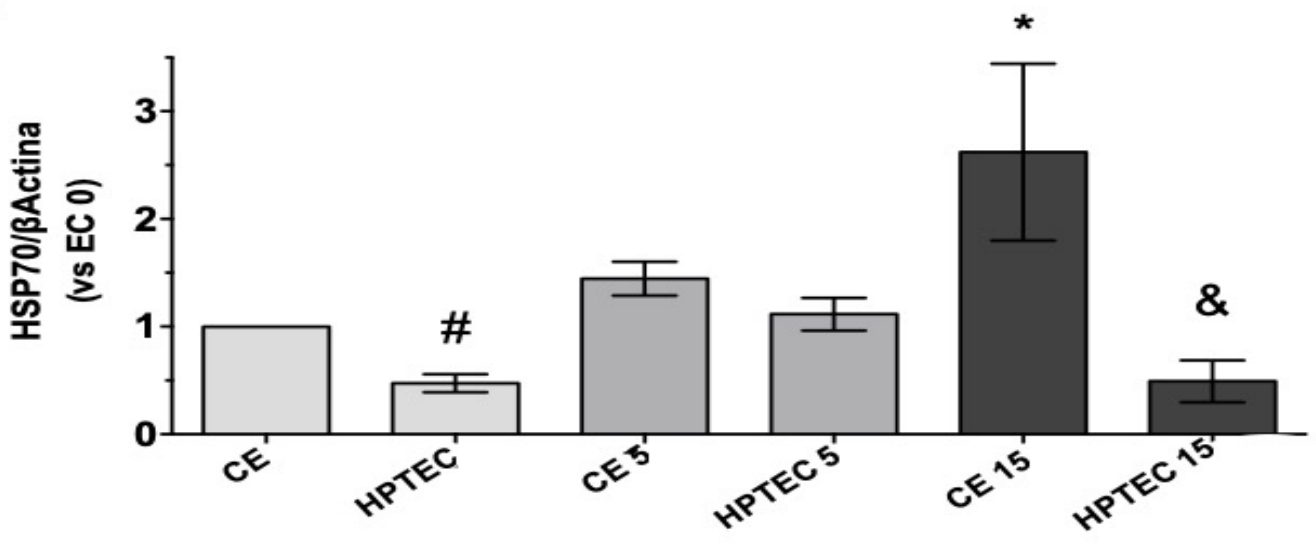

Figura 20- Efeito do shear stress na expressão proteica de HSP70

(A) Quantificação de HSP70 intracelular e normalizada por ß-actina, por western blot, nas condições: estática, shear stress 5 dynes $/ \mathrm{cm}^{2}$ e $15 \mathrm{dynes} / \mathrm{cm}^{2}$ durante vinte e quatro horas.

(B) Quantificação de HSP70, colunas representam a média \pm erro padrão $(n=7)$

(*) CE vs CE 15 (\#) HPTEC vs CE 15 (\&) CE 15 vs HPTEC $15 p<0,05$ (ANOVA com pós-teste Newman-keuls).

Abreviaturas: $\mathrm{HSP} 70=$ Heat Shock Protein 70/CE = células endoteliais na ausência de fluxo/HPTEC = hipertensão pulmonar tromboembólica crônica ausência de fluxo/CE 5 = células endoteliais expostas a $5 \mathrm{dynes} / \mathrm{cm}^{2}$ HPTEC 5 = células do grupo hipertensão pulmonar tromboembólica crônica expostas a $5 \mathrm{dynes} / \mathrm{cm}^{2} / \mathrm{CE} 15$ = células endoteliais expostas a 15 dynes $/ \mathrm{cm}^{2}$ / HPTEC 15 = células do grupo hipertensão pulmonar tromboembólica crônica expostas a $15 \mathrm{dynes} / \mathrm{cm}^{2}$. 
Na expressão da anexina A2 (Figura 21), existe uma tendência de níveis mais altos no estático no Grupo HPTEC. No shear as células dos pacientes não apresentaram aumento das expressões da A2. No controle ocorreu uma elevação discreta no alto e no baixo fluxo.

A

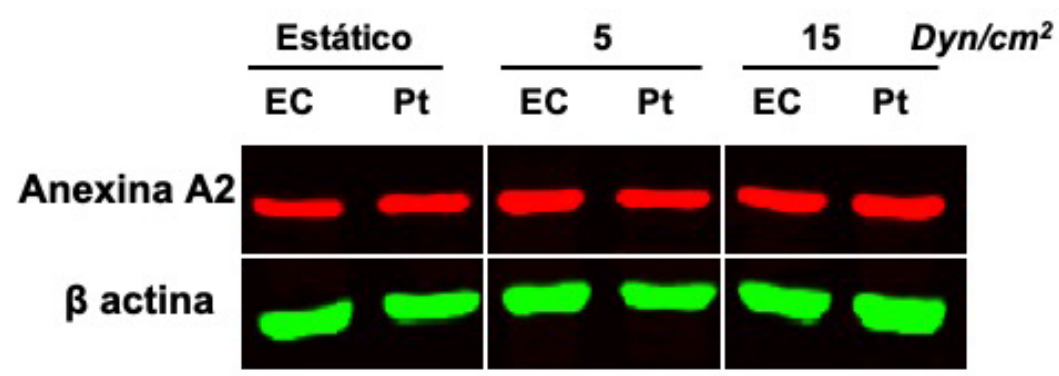

B

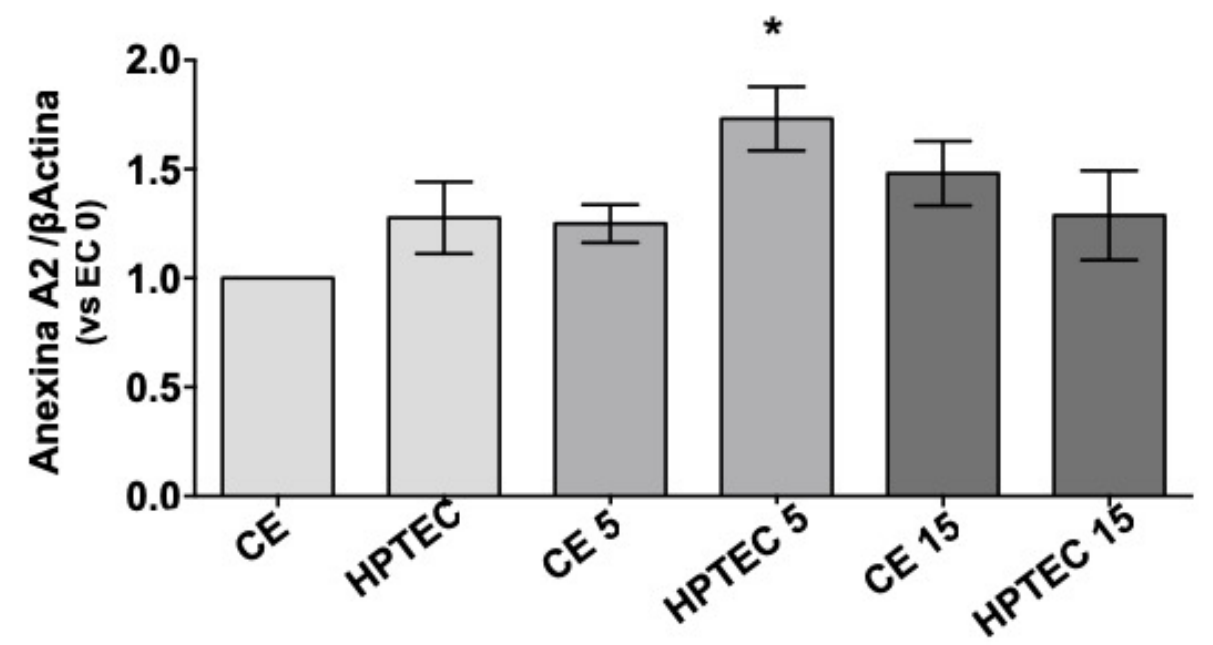

Figura 21- Efeito do shear stress na expressão proteica da anexina A2

(A) Quantificação de anexina A2 intracelular e normalizada por ß-actina, por western blot, nas condições: estática, shear stress 5 dynes $/ \mathrm{cm}^{2}$ e 15 dynes $/ \mathrm{cm}^{2}$ durante vinte e quatro horas.

(B) Quantificação de anexina A2, colunas representam a média \pm erro padrão $(n=7)$.

$\left(^{*}\right)$ CE vs HPTEC $5 p<0,05$ (ANOVA com pós-teste Newman-keuls).

Abreviaturas: $C E=$ células endoteliais na ausência de fluxo/HPTEC $=$ hipertensão pulmonar tromboembólica crônica ausência de fluxo/CE 5 = células endoteliais expostas a 5 dynes/ $\mathrm{cm}^{2} /$ HPTEC 5 = células do grupo hipertensão pulmonar tromboembólica crônica expostas a $5 \mathrm{dynes} / \mathrm{cm}^{2} / \mathrm{CE} 15$ = células endoteliais expostas a $15 \mathrm{dynes} / \mathrm{cm}^{2}$ / HPTEC 15 = células do grupo hipertensão pulmonar tromboembólica crônica expostas a 15 dynes $/ \mathrm{cm}^{2}$ 
$\mathrm{Na}$ avaliação imuno-histoquímica da parte interna da artéria pulmonar dos portadores de HPTEC foram realizadas marcações com HSP70 e anexina A2. Os achados demonstraram uma diminuição na expressão da HSP70. Porém, na anexina $A 2$, ocorreu um aumento da expressão. Nos dois casos os resultados foram comparados com artéria pulmonar de doadores de transplante pulmonar (Figura 22).
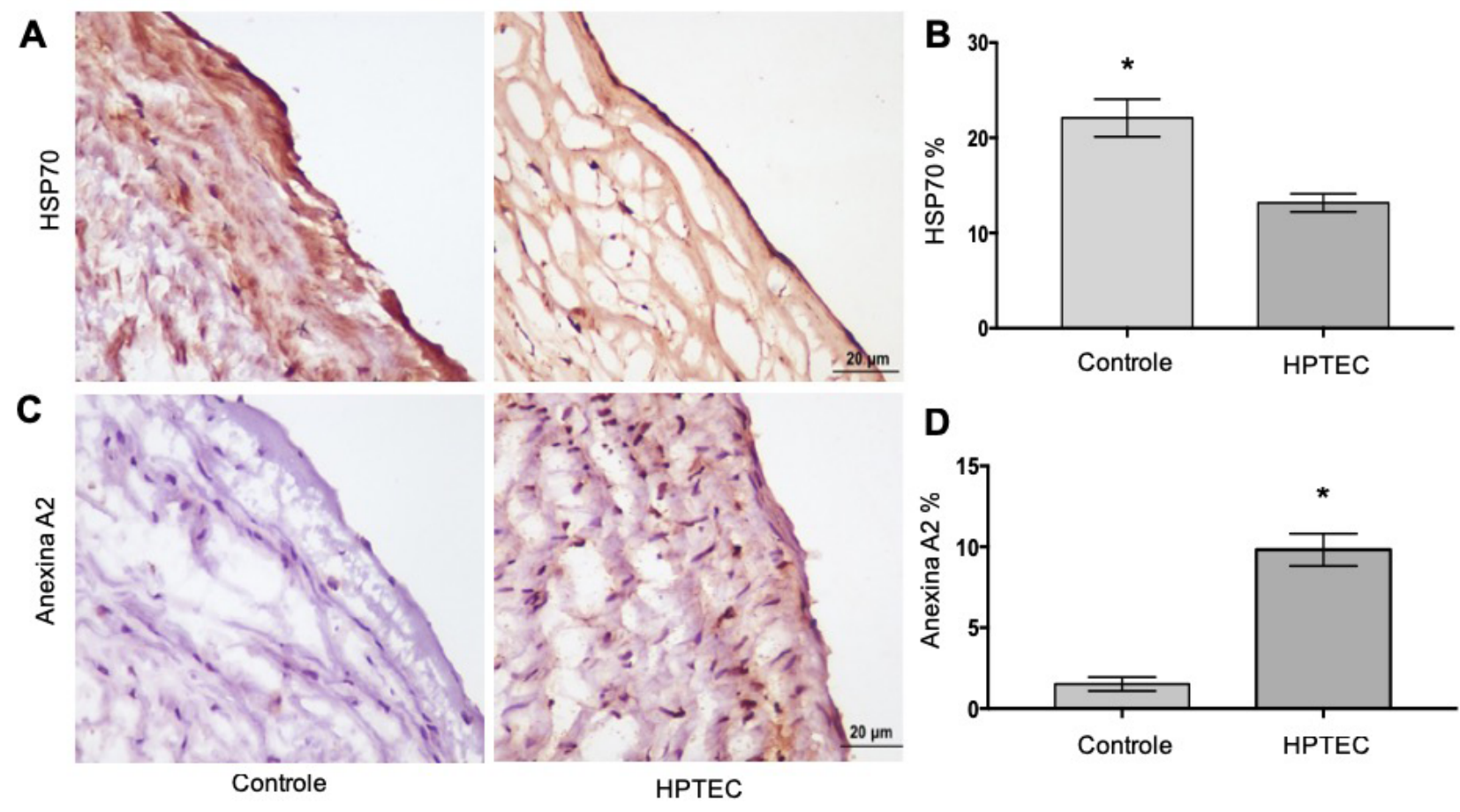

Figura 22- Marcação por imuno-histoquímica com HSP70 e anexina A2 na parte interna da artéria pulmonar dos portadores de HPTEC e artéria pulmonar de doadores de transplante pulmonar (controle)

(A) Marcação por imuno-histoquímica com HSP70

(B) Colunas representam a média \pm erro padrão $(n=7 \mathrm{HPTEC} / \mathrm{n}=4$ controle)

$\left.{ }^{*}\right)$ Controle vs HPTEC $p<0.05$ (teste $t$ não pareado).

(C) Marcação por imuno-histoquímica com anexina A2

(D) Colunas representam a média \pm erro padrão $(n=7 \mathrm{HPTEC} / \mathrm{n}=4$ controle)

${ }^{*}$ ) Controle vs HPTEC $p<0.05$ (teste $t$ não pareado).

Abreviaturas: HSP70 = Heat Shock Protein $70 /$ HPTEC $=$ hipertensão pulmonar tromboembólica crônica. 


\subsection{Experimentos submetidos à hipóxia}

A hipóxia tem um papel na fisiopatologia das doenças pulmonares. Foi avaliada a dosagem de nitrito pós vinte e quatro horas de hipóxia e seu valor comparado com o das culturas que permaneceram em normóxia. Estes resultados estão expressos na figura 23, onde é observada uma diminuição de nitrito após a hipóxia nos dois grupos. Entretanto, a hipóxia não foi capaz de identificar diferenças entre as células CE x HPTEC. Uma avaliação experimental, colocando as culturas após vinte e quatro horas de hipóxia no aparelho de shear, não demonstrou resultados diferentes das culturas que não foram colocadas na hipóxia.

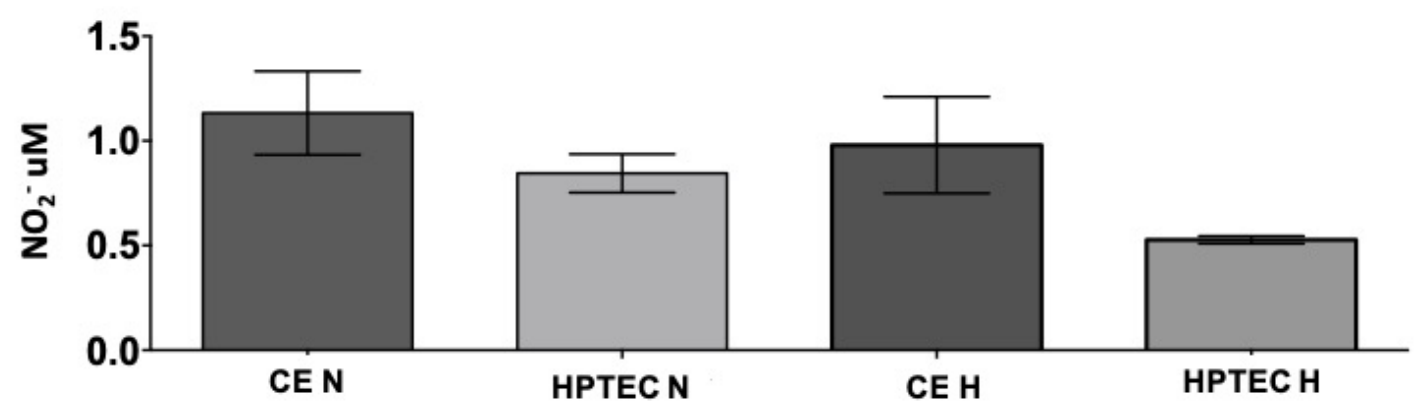

Figura 23- Quantificação da produção de NO do meio condicionado pré e pós vinte e quatro horas de hipóxia

Quantificação de nitrito no meio condicionado representando média \pm erro padrão. Não houve diferença estática $(n=4)$.

Abreviaturas: $\mathrm{CE} N$ = células endoteliais em normóxia / $\mathrm{CE} \mathrm{H}$ = células endoteliais em hipóxia / HPTEC $N$ = hipertensão pulmonar tromboembólica crônica em normóxia / HPTEC $\mathrm{H}=$ hipertensão pulmonar tromboembólica crônica em hipóxia / $\mathrm{NO}^{2-} \mathrm{uM}=$ dosagem de nitrito. 
5. Discussão 
Estudo recente sugere que o hiperfluxo pulmonar per se possa induzir o remodelamento vascular(55), que consiste de proliferação celular e disfunção endotelial( ${ }^{(9)}$, mesmo sem o desenvolvimento de $\mathrm{HP}^{(55)}$. Entretanto, nem todos os mecanismos envolvidos neste processo foram identificados, e os que já o foram precisam ser mais bem avaliados ${ }^{(9)}$. O estudo das células presentes na artéria pulmonar pode contribuir com informações importantes para melhor entendimento de todo o processo de alteração vascular. Em razão da retirada de trombos de pacientes portadores de HPTEC, é possível extrair partes da artéria pulmonar, como a região da íntima onde existem células endoteliais. Entretanto, é importante destacar que não há um método específico sobre a forma de extração dessas células, em maior parte desenvolvido a partir de estudos relacionados a artérias não pulmonares. Diante disto adaptou-se um protocolo usado para extração de células endoteliais coronárias ${ }^{(52)}$. Porém, a parte interna (íntima e muscular) das artérias pulmonares obtidas por TEAP é diferente da parte interna das artérias coronárias oriundas de cirurgias cardíacas. O material da primeira é mais fragmentado, tem o trombo aderido à parede do vaso, características que dificultam a retirada das células endoteliais. Foi o primeiro grande desafio desta pesquisa, padronizar uma forma de extração eficaz e confiável.

Neste estudo, as células com morfologia endotelial foram incubadas com CD31(2), um conhecido marcador positivo para este tipo celular; como controle negativo foi usado o CD90, que serve na identificação de células mesequimais ${ }^{(56)}$. Nos dois grupos, HPTEC e controle, encontraram-se praticamente $100 \%$ de marcação para CD31 e nenhum para CD90 (Figura 14), confirmando que as células extraídas dos trombos tinham características endoteliais. Além dos resultados positivos e semelhantes das marcações com CD31 nas culturas, os achados de expressão de eNOS e de óxido nítrico deixam claro que se trata de células endoteliais extraídas de artérias pulmonares.

Há muitos anos já se sabia que a presença de trombos na circulação pulmonar promovia uma redistribuição do sangue para um território desobstruído, induzindo um aumento da tensão nesses vasos ${ }^{(15)}$, entretanto ainda existem dúvidas de quais são as consequências dessas mudanças de fluxo. Na região da íntima dessas artérias, existe a expressão de proteínas, importantes reguladores da proteostase celular ${ }^{(28)}$, que agem estimuladas pelo 
fluxo sanguíneo e, dependendo deste, podem provocar maior ou menor liberação de $\mathrm{NO}^{(57)}$. Para mimetizar os diversos fluxos, as culturas foram colocadas no aparelho de shear stress em diferentes magnitudes (Figura 15). A partir deste procedimento foi possível dosar a expressão de proteínas em condições que simulam alto e baixo fluxo, reproduzindo o que ocorre na artéria pulmonar de portadores de HPTEC.

No estudo da via de expressão do NO, a eNOS exerce papel fundamental, e seus valores no grupo HPTEC foram reduzidos (Figura $16 \mathrm{~A}$ e B). Os dois grupos, quando submetidos a estímulo mecânico, apresentaram uma elevação da expressão na magnitude de 5 dynes $/ \mathrm{cm}^{2}$, porém no grupo HPTEC o aumento foi duas vezes maior quando comparado com a condição similar à ausência de fluxo, enquanto no grupo CE observou-se um pequeno incremento (Figuras 16 A e B). Na magnitude de 15 dynes $/ \mathrm{cm}^{2}$ ocorreu uma perda de resposta das células HPTEC, enquanto o grupo controle produziu aumentos duas vezes maiores quando comparada a condição estática (Figura 16 A e B). Tal fato demonstra um sinal de disfunção endotelial relacionada ao fluxo, corroborando a descrição de que aqueles de maior magnitude seriam mais prejudiciais na HPTEC( ${ }^{(9)}$.

Caveolina-1, alpha 5 integrina e HSP90 são proteínas importantes para ativação da eNOS ${ }^{(35,58)}$ que, analisadas em condições que simulam ausência de fluxo (Figura 17), apresentam apenas HSP90 com valores reduzidos na HPTEC (Figura 17 B). Estes achados sugerem uma nova forma de avaliar a disfunção endotelial desta doença.

Para melhor caracterização da via de ativação da eNOS, foi estudada a expressão de GRP94 no RE que, na condição estática, apresentou valores menores no grupo HPTEC (Figura 18). Em situações que simulam o alto fluxo foi encontrada uma redução ainda maior, demonstrando de forma mais clara a interferência desta condição na disfunção endotelial (Figura 18).

A produção de NO consiste numa função importante da célula endotelial ${ }^{(35)}$, alterada nos diferentes tipos de $\mathrm{HP}^{(59)}$. Vale destacar que tanto as células endoteliais sem doença (CE), quanto as dos pacientes com HPTEC apresentaram comportamento semelhante, com aumento da produção de NO quando submetidas a situações que simulam diferentes fluxos, com valores ainda maiores no de alta magnitude nos dois grupos (Figura $16 \mathrm{C}$ ). Nesta 
condição, a explicação para este resultado é que existem outras vias de ativação para a liberação de $\mathrm{NO}^{(57)}$, além da eNOS, e que não foram estudadas neste modelo. Outro fator importante é que as culturas foram submetidas a estímulo por um período de vinte e quatro horas, entretanto se desconhece quais seriam os resultados, caso fossem submetidas a exposições mais prolongadas em situações que simulassem alto fluxo. A permanência por maior tempo a fluxos sanguíneos elevados, antes da TEAP, parece ser pior in vivo, pois promove maior disfunção endotelial e quadro hemodinâmico mais acentuado, com piores resultados ao tratamento cirúrgico ${ }^{(60)}$. Entretanto, este protocolo de estudo não foi desenhado para testar esta hipótese.

As proteínas de choque térmico apresentam funções importantes na proteostase vascular(24). Em estudos relacionados à arteriosclerose, a HSP70 é descrita com função protetora importante, agindo na diminuição do processo inflamatório que promove a formação da placa de ateroma ${ }^{(42)}$. Recentemente foi descrita a ação da HSP70 intracelular em culturas de fibroblastos de pacientes com fibrose pulmonar idiopática, na qual se observou que a diminuição desta proteína contribuiu para o processo fibrótico nos pulmões ${ }^{(61)}$. Nesta pesquisa, no grupo HPTEC, encontrou-se redução da quantidade de HSP70 tanto em cultura celular como na imuno-histoquímica do tecido (Figuras 20 e 22). Deve-se ressaltar que em alto fluxo (shear stress de $15 \mathrm{dynes} / \mathrm{cm}^{2}$ ) os valores obtidos foram ainda menores. Estes resultados sugerem que nestas circunstâncias a resposta celular se esgota, mostrando, portanto, mais um sinal de disfunção endotelial em pacientes portadores de HPTEC.

Outros estudos demonstraram que as proteínas de choque térmico (HSP) podem passar para a superfície da membrana celular e interagir com o sistema de vigilância imunológica ou para o meio extracelular ${ }^{(62,63)}$. A HSP 70 tem a capacidade de migrar para o plasma, porém o mecanismo pelo qual isto acontece permanece incerto. Foi descrito que a intensidade do shear stress nas células endoteliais da circulação sistêmica tem relação com esta liberação( ${ }^{64)}$. Em doenças como síndrome coronariana aguda, aterosclerose associada à hipertensão arterial e insuficiência cardíaca $(42,63,65,66)$, a HSP70 apresenta efeito cardioprotetor $^{(62)}$, e a dosagem plasmática desta proteína revela que valores mais baixos são relacionados com pior prognóstico. Estes dados sobre HSP70 
extracelular nas doenças cardiovasculares e os resultados de menor expressão desta proteína, obtidos no grupo HPTEC, sinalizam para a necessidade de investigar quais valores plasmáticos da HSP70 seriam mais adequados para sua utilização clínica. Também seria interessante realizar projetos de pesquisa que pudessem determinar a eventual relação de seus valores com o prognóstico de pacientes com HPTEC. Estudos futuros poderiam comparar os resultados obtidos no sangue da artéria pulmonar no pré e pós-operatório de pacientes submetidos à TEAP aos coletados, no mesmo momento, em vasos periféricos. Em caso de concordância, abre-se a possibilidade de obter esta informação sobre HSP70 de maneira menos invasiva e de maior praticidade clínica.

Novos protocolos também avaliariam os níveis desta proteína como fator de gravidade da doença, comparando-a, por exemplo, a medidas hemodinâmicas, como débito cardíaco e resistência vascular pulmonar, que são marcadores importantes de comprometimento da circulação pulmonar. Dependendo dos resultados encontrados, poder-se-ia pensar no uso de HSP70 extracelular como biomarcador da doença. Ampliar esta pesquisa para outras formas de HP seria promissor e, eventualmente, contribuiria para a orientação desses pacientes.

A GRP78 é outra proteína do RE com ação protetora ${ }^{(44)}$. Sua função é descrita como semelhante à HSP70, com expressão relacionada ao fluxo sanguíneo ao qual o sistema está submetido; sua quantificação poderia ser um marcador do stress sofrido pelo RE na doença arteriosclerótica ${ }^{(67)}$. Em um estudo experimental(68), com infusão de monocrotalina para induzir HP, foi demonstrado que existe stress do RE já na fase inicial, com aumentos da expressão de GRP78 após o terceiro dia do início das infusões. Com este resultado ficou evidenciado que as alterações sofridas pelo RE podem ocorrer antes da identificação do aumento da pressão na artéria pulmonar(68). Em nosso estudo, os valores de GRP78 (Figuras 19 A e B) aumentaram nos dois grupos quando submetidos a stress mecânico, apontando que as culturas responderam ao fluxo a que foram submetidas. No shear de baixa intensidade, os valores foram semelhantes aos do controle; porém, na alta magnitude, mostraram resultados inferiores nas culturas dos pacientes com HPTEC. Diante desse achado sugere-se que o sistema de shear tenha estimulado stress do RE, que refletiu aumento de 
GRP78; portanto, mais uma vez, em situações características de altos fluxos, ocorreu um esgotamento da resposta celular. Tal alteração também pode ser um sinal importante do comprometimento das células endoteliais nas artérias pulmonares dos pacientes com HPTEC.

Dentro do RE e com papel importante no processo inicial da coagulação, existe a PDI, com função moduladora para outras proteínas na formação do trombo(46). Estudar sua expressão neste modelo poderia trazer informações relevantes do processo inicial de sua formação, entretanto não foram encontradas diferenças entre os grupos estudados (Figuras 19 A e C). Porém, devemos considerar que, na maioria das vezes, na HPTEC, o trombo é originário dos membros inferiores, migra e impacta a artéria pulmonar, não existindo, portanto, uma ação direta dos vasos pulmonares em sua formação. A relação entre a trombose in situ pulmonar e a PDI ainda merece investigação mais aprofundada.

No processo microvascular do complexo de fibrinólise, a anexina A2 é a proteína responsável pela ativação do plasminogênio para a produção de plasmina e consequente formação do trombo(47). Por este motivo, estudar os processos envolvidos na dissolução dos coágulos torna-se interessante e pode fornecer informações importantes da fisiopatologia da HPTEC. Na marcação imuno-histoquímica do tecido com anexina $A 2$, foi encontrado um aumento da expressão, levando à ideia de que a presença do trombo na artéria pulmonar poderia estimular o sistema à fibrinólise (Figura 22). Nas culturas ocorreu o mesmo resultado somente em situações que simulam o baixo fluxo (Figura 21), nas outras análises não houve diferenças. Estes achados expõem a necessidade de um estudo mais aprofundado do complexo de fibrinólise, composto por uma série de mediadores que não foram avaliados neste protocolo.

A relação entre a HPTEC e a hipóxia já foi demonstrada previamente ${ }^{(69)}$, entretanto a descrição de alterações na microvasculatura pulmonar é mais recente, pelo estudo dos vasos pulmonares por meio de biópsia de pulmão realizada concomitantemente à $\operatorname{TEAP}^{(70)}$. No estudo de Jujo e colaboradores ${ }^{(70)}$, foi possível associar a gravidade da arteriopatia pulmonar com a pressão parcial de oxigênio $\left(\mathrm{PaO}_{2}\right)$, revelando que quanto mais graves as alterações na artéria 
pulmonar, menor a concentração de oxigênio(70). Nesta pesquisa as culturas foram submetidas à hipóxia por vinte e quatro horas e foi possível notar uma diminuição da produção de NO nos dois grupos, quando comparados à normóxia (Figura 23); entretanto não foram observadas diferenças entre as culturas controle e HPTEC. Também foram realizadas avaliações experimentais pela colocação das células por vinte e quatro horas na hipóxia antes da realização do stress mecânico. Entretanto, quando foi avaliada a expressão de eNOS, não foram observados resultados diferentes, razão pela qual optou-se por não prosseguir com esta parte do experimento. Uma das explicações para os resultados não serem diferentes das culturas não colocadas em hipóxia previamente é que os experimentos eram feitos de forma separada, ou seja, primeiro as culturas eram colocadas na hipóxia e, posteriormente, no stress mecânico. O ideal seria a realização concomitante de hipóxia + shear; porém, tecnicamente, tal ensaio não foi possível.

Desde que Sakao e colaboradores(2) identificaram que as células extraídas dos trombos de indivíduos com HPTEC eram diferente das normais, um novo conceito fisiopatológico começou a ser discutido. Ficou clara a necessidade do estudo das diversas proteínas envolvidas na proteostase celular, da mesma maneira como já foi realizada em outras doenças pulmonares que acarretam stress das vias respiratórias, como o enfisema e a asma(71). Embora os dados precisem ser confirmados in vivo, o melhor entendimento da disfunção endotelial que ocorre nos pacientes com HPTEC é muito importante para que se possa lidar com esta grave doença pulmonar circulatória. A perda de resposta, decorrente da alteração da função celular em situação de alto fluxo, pode estar relacionada a doença mais grave, decorrente de um importante comprometimento da proteostase celular.

Entre as limitações desta pesquisa, deve-se destacar a pequena quantidade de culturas analisadas, situação que pode ser explicada pelo grande número de repetições necessárias para confirmação dos resultados e para a padronização de métodos ainda pouco utilizados em trabalhos com células endoteliais de artérias pulmonares. É relevante citar que este protocolo não tem a abrangência necessária para avaliar todas as vias de ativação da eNOS e não pode explicar a razão de existir uma diminuição da expressão desta proteína em portadores de HPTEC com produção de NO mantidas. 
Neste estudo, apesar das dificuldades encontradas, o esclarecimento de novos mecanismos fisiopatológicos envolvidos na disfunção endotelial de células de artérias pulmonares da população estudada foi muito importante. Este resultado contribui para melhor entendimento deste processo, possivelmente ajude a encontrar outros marcadores de sobrevida e novas vias de tratamento desta doença.

Sabe-se que a TEAP é a melhor terapêutica para esta afecção, porém em alguns pacientes ela não é possível e, em outros, mesmo após o procedimento cirúrgico, persiste HP residual, piorando a qualidade de vida e limitando o prognóstico. Diante deste fato, entender melhor a fisiopatologia da HPTEC pode produzir melhor tratamento para esses indivíduos na prática clínica diária e proporcionar vida mais longa e de qualidade para esses pacientes. 
6. Conclusão 
1 - A avaliação morfológica revelou que as células retiradas dos portadores de HPTEC são endoteliais, com marcação positiva para CD31.

2 - Do ponto de vista funcional, as células apresentaram sinais de comprometimento da homeostase proteica, evidenciados pela diminuição da expressão de eNOS e HSP90. A alteração da proteostase ficou mais evidente pela perda de resposta da eNOS, HSP70, GRP78 e GRP94, quando utilizado shear stress de alta magnitude. De maneira semelhante ao encontrado nas culturas, houve redução da expressão de HSP70 no tecido de artérias pulmonares de portadores de HPTEC. Na avaliação dos mesmos vasos para marcação com anexina A2, observou-se aumento da expressão, sugerindo estímulo ao complexo de fibrinólise. A hipóxia reduziu a produção de NO, mas sem diferenciar os grupos celulares investigados. 


\section{Anexos}




\title{
7.1 Anexo A: Aprovação do Projeto de Pesquisa
}

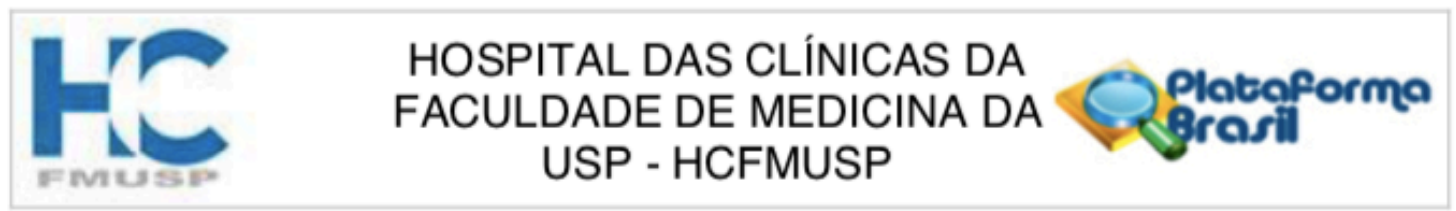

\section{PARECER CONSUBSTANCIADO DO CEP}

\section{DADOS DO PROJETO DE PESQUISA}

Título da Pesquisa: Caracterização morfológica e funcional de células de artérias pulmonares em cultura provenientes de pacientes com tromboembolismo pulmonar crônico hipertensivo

Pesquisador: Mario Terra Filho

Área Temática:

Versão: 2

CAAE: 40583115.8 .0000 .0068

Instituição Proponente: HOSPITAL DAS CLINICAS DA FACULDADE DE MEDICINA DA U S P

Patrocinador Principal: HOSPITAL DAS CLINICAS DA FACULDADE DE MEDICINA DA U S P CONS NAC DE DESENVOLVIMENTO CIENTIFICO E TECNOLOGICO

\section{DADOS DO PARECER}

Número do Parecer: 1.051 .734

Data da Relatoria: 25/02/2015

\begin{abstract}
Apresentação do Projeto:
Protocolo in vitro a ser desenvolvido em 48 meses utilizando material coletado de pacientes com tromboembolismo pulmonar crônico hipertensivo durante cirurgia de desentupimento arterial. A doença está associada à obliteração de grandes e pequenos vasos pulmonares e ao remodelamento vascular. Este é caracterizado pela proliferação desordenada de células endoteliais, musculares lisas e miofibroblastos. A importância de estímulos como hipóxia e shear stress pode trazer benefícios para o tratamento da enfermidade.
\end{abstract}

\section{Objetivo da Pesquisa:}

Caracterizar as células em cultura provenientes de artéria pulmonar de pacientes com TEPCH e avaliar o efeito da hipóxia e do shear stress na apoptose e na proliferação de células endoteliais.

\section{Avaliação dos Riscos e Benefícios:}

trata-se de risco mínimo uma vez que o procedimento cirúrgico era indicado

Comentários e Considerações sobre a Pesquisa:

Metodologia pertinente

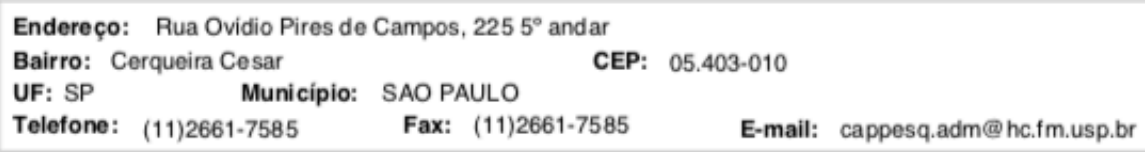




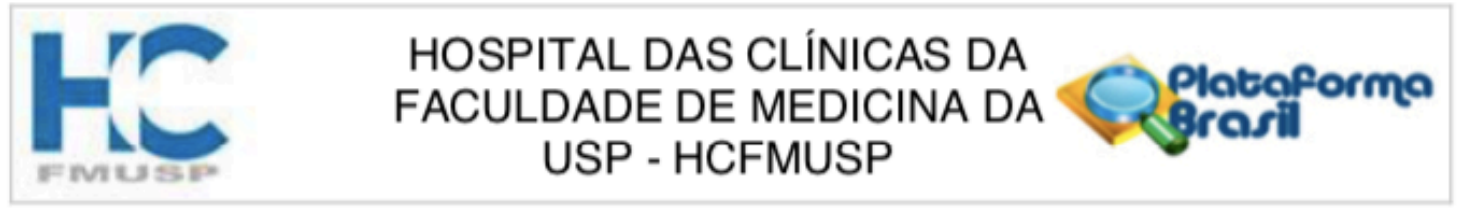

Continuaçắo do Parecer: 1.051 .734

Considerações sobre os Termos de apresentação obrigatória:

Todos estão apresentados e TCLE claro para o paciente

Recomendações:

O material biológico não será armazenado

Conclusões ou Pendências e Lista de Inadequações:

Sem Pendências

Situação do Parecer:

Aprovado

Necessita Apreciação da CONEP:

Não

Consideraçỗes Finais a critério do CEP:

SAO PAULO, 06 de Maio de 2015

Assinado por:

ALFREDO JOSE MANSUR

(Coordenador)

Endereço: Rua Ovidio Pires de Campos, $2255^{\circ}$ andar

Bairro: Cerqueira Cesar

CEP: $\quad 05.403-010$

UF: SP Municipio: SAO PAULO

Telefone: (11)2661-7585 Fax: (11)2661-7585 E-mail: cappesq.adm @ hc.fm.usp.br 
1. Simonneau G, Gatzoulis MA, Adatia I, Celermajer D, Denton C, Ghofrani $A$, et al. Updated clinical classification of pulmonary hypertension. J Am Coll Cardiol. 2013;62(25 Suppl):D34-41.

2. Sakao S, Hao H, Tanabe N, Kasahara Y, Kurosu K, Tatsumi K. Endothelial-like cells in chronic thromboembolic pulmonary hypertension: crosstalk with myofibroblast-like cells. Respir Res. 2011;12:109.

3. Delcroix M, Kerr K, Fedullo P. Chronic Thromboembolic Pulmonary Hypertension. Epidemiology and Risk Factors. Ann Am Thorac Soc. 2016;13 Suppl 3:S201-6.

4. Lang IM, Madani M. Update on chronic thromboembolic pulmonary hypertension. Circulation. 2014;130(6):508-18.

5. Mercier O, Fadel E. Chronic thromboembolic pulmonary hypertension: animal models. Eur Respir J. 2013;41(5):1200-6.

6. Jenkins D. Pulmonary endarterectomy: the potentially curative treatment for patients with chronic thromboembolic pulmonary hypertension. Eur Respir Rev. 2015;24(136):263-71.

7. Terra-Filho M, Mello MF, Lapa MS, Teixeira RH, Jatene FB. Clinical and haemodynamic evaluation of chronic thromboembolic pulmonary hypertension patients scheduled for pulmonary thromboendarterectomy: Is schistosomiasis hypertension an important confounding factor? Clinics. 2010;65(11):1155-60.

8. Jamieson SW, Kapelanski DP, Sakakibara N, Manecke GR, Thistlethwaite PA, Kerr KM, et al. Pulmonary endarterectomy: experience and lessons learned in 1,500 cases. Ann Thorac Surg. 2003;76(5):1457-62; discussion 62-4.

9. Lang IM, Dorfmuller P, Vonk Noordegraaf A. The Pathobiology of Chronic Thromboembolic Pulmonary Hypertension. Ann Am Thorac Soc. 2016;13 Suppl 3:S215-21.

10. Fernandes T, Planquette B, Sanchez O, Morris T. From Acute to Chronic Thromboembolic Disease. Ann Am Thorac Soc. 2016;13 Suppl 3:S207-14.

11. Xie Y, Muller WA. Molecular cloning and adhesive properties of murine platelet/endothelial cell adhesion molecule 1. Proc Natl Acad Sci U S A. 1993;90(12):5569-73.

12. Bonderman D, Jakowitsch J, Redwan B, Bergmeister $H$, Renner MK, Panzenbock $\mathrm{H}$, et al. Role for staphylococci in misguided thrombus resolution of chronic thromboembolic pulmonary hypertension. Arterioscler Thromb Vasc Biol. 2008;28(4):678-84.

13. Dorfmuller P, Gunther S, Ghigna MR, Thomas de Montpreville V, Boulate $\mathrm{D}$, Paul JF, et al. Microvascular disease in chronic thromboembolic pulmonary hypertension: a role for pulmonary veins and systemic vasculature. Eur Respir J. 2014;44(5):1275-88.

14. Simonneau G, Torbicki A, Dorfmuller P, Kim N. The pathophysiology of chronic thromboembolic pulmonary hypertension. Eur Respir Rev. 2017;26(143).

15. Moser KM, Bloor CM. Pulmonary vascular lesions occurring in patients with chronic major vessel thromboembolic pulmonary hypertension. Chest. 1993;103(3):685-92.

16. Piazza G, Goldhaber SZ. Chronic thromboembolic pulmonary hypertension. N Engl J Med. 2011;364(4):351-60.

17. Firasat S, Hecker M, Binder L, Asif AR. Advances in endothelial shear stress proteomics. Expert Rev Proteomics. 2014;11(5):611-9. 
18. Yurdagul A, Jr., Finney AC, Woolard MD, Orr AW. The arterial microenvironment: the where and why of atherosclerosis. Biochem $\mathrm{J}$. 2016;473(10):1281-95.

19. Happe CM, Szulcek R, Voelkel NF, Bogaard HJ. Reconciling paradigms of abnormal pulmonary blood flow and quasi-malignant cellular alterations in pulmonary arterial hypertension. Vascul Pharmacol. 2016;83:17-25.

20. Sakao S, Tatsumi K. Crosstalk between endothelial cell and thrombus in chronic thromboembolic pulmonary hypertension: perspective. Histol Histopathol 2013;28:185-93.

21. Sakao S, Taraseviciene-Stewart L, Lee J, Wood K, Cool C, Voelkel N. Initial apoptosis is followed by increased proliferation of apoptosis-resistant endothelial cells. FASEB J. 2005;1178-80.

22. Masri FA, Xu W, Comhair SA, Asosingh $K$, Koo M, Vasanji A, et al. Hyperproliferative apoptosis-resistant endothelial cells in idiopathic pulmonary arterial hypertension. Am J Physiol Lung Cell Mol Physiol. 2007;293(3):L548-54. 23. Labbadia J, Morimoto RI. The biology of proteostasis in aging and disease. Annu Rev Biochem. 2015;84:435-64.

24. Powers ET, Balch WE. Diversity in the origins of proteostasis networks--a driver for protein function in evolution. Nat Rev Mol Cell Biol. 2013;14(4):237-48. 25. Balch WE, Morimoto RI, Dillin A, Kelly JW. Adapting proteostasis for disease intervention. Science. 2008;319(5865):916-9.

26. Gidalevitz T, Prahlad V, Morimoto RI. The stress of protein misfolding: from single cells to multicellular organisms. Cold Spring Harb Perspect Biol. $2011 ; 3(6)$.

27. Laurindo FRM, Araujo TLS, Fernandes DC. Biologia da Parede do Vaso. Kalil Filho R, Fuster V, editors. Medicina cardiovascular: reduzindo o impacto das doenças. São Paulo: Atheneu; 2016. p. 89-106.

28. Aman J WE, van Nieuw Amerongen GP, Malik AB, van Hinsbergh VW. Using cultured endothelial cells to study endothelial barrier dysfunction: Challenges and opportunities. Am J Physiol Lung Cell Mol Physiol. 2016.

29. Furchgott RF, Zawadzki JV. The obligatory role of endothelial cells in the relaxation of arterial smooth muscle by acetylcholine. Nature. 1980;288(5789):373-6.

30. Harrison DG, Cai $\mathrm{H}$. Endothelial control of vasomotion and nitric oxide production. Cardiol Clin. 2003;21(3):289-302.

31. Green LC, Tannenbaum SR, Goldman P. Nitrate synthesis in the germfree and conventional rat. Science. 1981;212(4490):56-8.

32. Tannenbaum SR, Fett D, Young VR, Land PD, Bruce WR. Nitrite and nitrate are formed by endogenous synthesis in the human intestine. Science. 1978;200(4349):1487-9.

33. $\mathrm{Li} \mathrm{H}$, Forstermann $\mathrm{U}$. Nitric oxide in the pathogenesis of vascular disease. J Pathol. 2000;190(3):244-54.

34. Laurindo FRM, Liberman M, Leite PF. Substâncias vasodilatadoras produzidas pelo endotélio. Luz PL, Laurindo FRM, Chagas ACP, editors. Endotélio e Doenças Cardiovasculares. São Paulo: Atheneu; 2005. p. 33-42.

35. Vanhoutte PM, Zhao Y, Xu A, Leung SW. Thirty Years of Saying NO: Sources, Fate, Actions, and Misfortunes of the Endothelium-Derived Vasodilator Mediator. Circ Res. 2016;119(2):375-96. 
36. Balligand JL, Feron O, Dessy C. eNOS activation by physical forces: from short-term regulation of contraction to chronic remodeling of cardiovascular tissues. Physiol Rev. 2009;89(2):481-534.

37. Marzec M, Eletto D, Argon Y. GRP94: An HSP90-like protein specialized for protein folding and quality control in the endoplasmic reticulum. Biochim Biophys Acta. 2012;1823(3):774-87.

38. De Maio A, Santoro MG, Tanguay RM, Hightower LE. Ferruccio Ritossa's scientific legacy 50 years after his discovery of the heat shock response: a new view of biology, a new society, and a new journal. Cell Stress Chaperones. 2012;17(2):139-43.

39. Wu C. Heat shock transcription factors: structure and regulation. Annu Rev Cell Dev Biol. 1995;11:441-69.

40. Genest O, Wickner S, Doyle SM. Hsp90 and Hsp70 chaperones: Collaborators in protein remodeling. J Biol Chem. 2018.

41. Buchberger A, Bukau B, Sommer T. Protein quality control in the cytosol and the endoplasmic reticulum: brothers in arms. Mol Cell. 2010;40(2):238-52.

42. Pockley AG, Georgiades A, Thulin T, de Faire U, Frostegard J. Serum heat shock protein 70 levels predict the development of atherosclerosis in subjects with established hypertension. Hypertension. 2003;42(3):235-8.

43. Pockley AG, Calderwood SK, Multhoff G. The atheroprotective properties of Hsp70: a role for Hsp70-endothelial interactions? Cell Stress Chaperones. 2009;14(6):545-53.

44. Feaver RE, Hastings NE, Pryor A, Blackman BR. GRP78 upregulation by atheroprone shear stress via p38-, alpha2beta1-dependent mechanism in endothelial cells. Arterioscler Thromb Vasc Biol. 2008;28(8):1534-41.

45. Hang Q, Isaji T, Hou S, Wang Y, Fukuda T, Gu J. A Key Regulator of Cell Adhesion: Identification and Characterization of Important N-Glycosylation Sites on Integrin alpha5 for Cell Migration. Mol Cell Biol. 2017;37(9).

46. Popescu NI, Lupu C, Lupu F. Extracellular protein disulfide isomerase regulates coagulation on endothelial cells through modulation of phosphatidylserine exposure. Blood. 2010;116(6):993-1001.

47. Luo M, Hajjar KA. Annexin A2 system in human biology: cell surface and beyond. Semin Thromb Hemost. 2013;39(4):338-46.

48. Flood EC, Hajjar KA. The annexin A2 system and vascular homeostasis. Vascul Pharmacol. 2011;54(3-6):59-67.

49. Hajjar KA. The Biology of Annexin A2: From Vascular Fibrinolysis to Innate Immunity. Trans Am Clin Climatol Assoc. 2015;126:144-55.

50. Sciascia S, Baldovino S, Schreiber K, Solfietti L, Radin M, Cuadrado MJ, et al. Thrombotic risk assessment in antiphospholipid syndrome: the role of new antibody specificities and thrombin generation assay. Clin Mol Allergy. 2016;14:6. 51. Cesarman-Maus G, Hajjar KA. Molecular mechanisms of fibrinolysis. Br J Haematol. 2005;129(3):307-21.

52. Campos LC, Miyakawa AA, Barauna VG, Cardoso L, Borin TF, Dallan LA, et al. Induction of CRP3/MLP expression during vein arterialization is dependent on stretch rather than shear stress. Cardiovasc Res. 2009;83(1):140-7.

53. Firth AL, Yao W, Ogawa A, Madani MM, Lin GY, Yuan JX. Multipotent mesenchymal progenitor cells are present in endarterectomized tissues from patients with chronic thromboembolic pulmonary hypertension. Am J Physiol Cell Physiol. 2010;298(5):C1217-25. 
54. Nickel N, Jonigk D, Kempf T, Bockmeyer CL, Maegel L, Rische J, et al. GDF-15 is abundantly expressed in plexiform lesions in patients with pulmonary arterial hypertension and affects proliferation and apoptosis of pulmonary endothelial cells. Respir Res. 2011;12:62.

55. Rol N, Happe C, Belien JAM, de Man FS, Westerhof N, Vonk-Noordegraaf $A$, et al. Vascular remodelling in the pulmonary circulation after major lung resection. Eur Respir J. 2017;50(2).

56. Moazen B, Zarrinhaghighi A, Nejatollahi F. Selection and Evaluation of Specific Single Chain Antibodies against CD90, a Marker for Mesenchymal and Cancer Stem Cells. Rep Biochem Mol Biol. 2018;7(1):45-51.

57. Vanhoutte PM, Shimokawa H, Feletou M, Tang EH. Endothelial dysfunction and vascular disease - a 30th anniversary update. Acta Physiol (Oxf). 2017;219(1):22-96.

58. Christofidou-Solomidou M, Bridges M, Murphy GF, Albelda SM, DeLisser $H M$. Expression and function of endothelial cell alpha $v$ integrin receptors in wound-induced human angiogenesis in human skin/SCID mice chimeras. Am J Pathol. 1997;151(4):975-83.

59. Klinger JR, Kadowitz PJ. The Nitric Oxide Pathway in Pulmonary Vascular Disease. Am J Cardiol. 2017;120(8S):S71-S9.

60. Jenkins D, Madani M, Fadel E, D'Armini AM, Mayer E. Pulmonary endarterectomy in the management of chronic thromboembolic pulmonary hypertension. Eur Respir Rev. 2017;26(143).

61. Sellares J, Veraldi KL, Thiel KJ, Cardenes N, Alvarez D, Schneider F, et al. Intracellular Heat Shock Protein 70 Deficiency in Pulmonary Fibrosis. Am J Respir Cell Mol Biol. 2018.

62. Zhu J, Quyyumi AA, Wu H, Csako G, Rott D, Zalles-Ganley A, et al. Increased serum levels of heat shock protein 70 are associated with low risk of coronary artery disease. Arterioscler Thromb Vasc Biol. 2003;23(6):1055-9.

63. Pockley AG. Heat shock proteins, inflammation, and cardiovascular disease. Circulation. 2002;105(8):1012-7.

64. Calderwood SK, Mambula SS, Gray PJ, Jr., Theriault JR. Extracellular heat shock proteins in cell signaling. FEBS Lett. 2007;581(19):3689-94.

65. Zhang X, Tanguay RM, He M, Deng Q, Miao X, Zhou L, et al. Variants of HSPA1A in combination with plasma Hsp70 and anti-Hsp70 antibody levels associated with higher risk of acute coronary syndrome. Cardiology. 2011;119(1):57-64.

66. Jenei ZM, Gombos T, Forhecz Z, Pozsonyi Z, Karadi I, Janoskuti L, et al. Elevated extracellular HSP70 (HSPA1A) level as an independent prognostic marker of mortality in patients with heart failure. Cell Stress Chaperones. 2013;18(6):809-13.

67. Zhou J, Werstuck GH, Lhotak S, de Koning AB, Sood SK, Hossain GS, et al. Association of multiple cellular stress pathways with accelerated atherosclerosis in hyperhomocysteinemic apolipoprotein E-deficient mice. Circulation. 2004;110(2):207-13.

68. Wang JJ, Zuo XR, Xu J, Zhou JY, Kong H, Zeng XN, et al. Evaluation and Treatment of Endoplasmic Reticulum (ER) Stress in Right Ventricular Dysfunction during Monocrotaline-Induced Rat Pulmonary Arterial Hypertension. Cardiovasc Drugs Ther. 2016;30(6):587-98. 
69. Kapitan KS, Buchbinder M, Wagner PD, Moser KM. Mechanisms of hypoxemia in chronic thromboembolic pulmonary hypertension. Am Rev Respir Dis. 1989;139(5):1149-54.

70. Jujo T, Tanabe N, Sakao S, Ishibashi-Ueda H, Ishida K, Naito A, et al. Severe Pulmonary Arteriopathy Is Associated with Persistent Hypoxemia after Pulmonary Endarterectomy in Chronic Thromboembolic Pulmonary Hypertension. PLoS One. 2016;11(8):e0161827.

71. Bouchecareilh M, Balch WE. Proteostasis: a new therapeutic paradigm for pulmonary disease. Proc Am Thorac Soc. 2011;8(2):189-95. 